\title{
English Learner Curricular Streams in Four Middle Schools: Triage in the Trenches
}

\author{
Peggy Estrada
}

Published online: 7 May 2014

(C) The Author(s) 2014. This article is published with open access at Springerlink.com

\begin{abstract}
Little is known about the curricular experiences schools provide English learner students (ELs) to meet the dual goals of attaining English language proficiency (ELP) and grade-level achievement. I introduce the concept of Curricular Streams to provide a more nuanced comparative analysis of four urban middle schools, focusing on: (a) the extent to which they provided English language development (ELD) instruction and access to the core and full curriculum; and (b) the relative emphasis on ELP versus core academic content, remediation versus acceleration, and isolation versus integration of ELs with non-EL peers. I situate the Curricular Streams within the schools' broader cultures and practices. The results reveal local definitions of EL status and wide variation in EL Curricular Streams: One school emphasized ELP and remediation over access to the core. Another integrated ELs more quickly into mainstream courses, yet its remediation emphasis limited access to the core. The third provided more access, but isolated ELs. The fourth provided more access to the core, accelerated ELD, and eschewed interventions. The evidence suggests that schools are groping for solutions and it raises questions about the efficacy of EL state policy that relies on local control for interpretation. I provide implications for research, policy, and practice and hypotheses about the characteristics of Curricular Streams and school cultures that might increase ELs' opportunity to learn and achieve the dual goals.
\end{abstract}

Keywords English learners - Middle school - Curricular Streams · English language development $\cdot$ Access to core curricula $\cdot$ Reclassification

\footnotetext{
P. Estrada $(\bowtie)$

Latin American and Latino Studies Department, Merrill Faculty Services, University of California, 1156 High St., Santa Cruz, CA 95064, USA

e-mail: peggye@ucsc.edu
} 


\section{Introduction}

Persistent underachievement and its consequences for diminished life chances lend urgency to developing effective educational policies and practices for English learners (ELs), students with a home language other than English who have not met English proficiency criteria. California is home to $33 \%$ of ELs in the United States, ${ }^{1}$ ELs make up $23.2 \%$ of its K-12 students (California Department of Education [CDE] 2011a), and $85 \%$ are Spanish speakers (CDE 2012a). Nationally, ELs make up $10.7 \%$ of all pre-K-12 students, $77 \%$ are Spanish speaking (U.S. Department of Education 2008-2009), and they are increasing faster than any other group, with $53.2 \%$ growth for ELs versus $8.5 \%$ for all students during the span 1997-1998 to 2007-2008 (Batalova and McHugh 2010a, b). Although California has more ELs than the other five most impacted states combined (Texas, Florida, New York, Illinois, and Arizona), during this 10-year span, 11 other sates saw increases of over $200 \%$ in EL enrollment. Thus, California portends the future for much of the rest of the country (Batalova and McHugh 2010a).

The CDE's goal for its nearly 1.4 million ELs, who are legally entitled to language and instructional support services (CDE 2006), is rapid and effective development of full proficiency in English on par with native speakers and achievement of grade-level academic content standards within a reasonable time period (CDE 2012b). Yet, California faces at least three distinct challenges in educating its ELs, which available research suggests are similar across the nation (e.g., Abedi 2008; Abedi and Dietel 2004; Ragan and Lesaux 2006; Ruiz-deVelasco and Fix 2000; Working Group on ELL Policy 2010). First, ELs continue to underachieve despite increasing federal and state accountability requirements. For example, in 2010-2011, 29 \% of California's second-grade ELs (who had been enrolled in a US school 12 or more months) performed 2 or more years below grade level in language arts compared to $17 \%$ of English only (EO) students; $69 \%$ of EL high school juniors did so, compared to $23 \%$ of EO students (CDE 2011b, c). Nationally, ELs on average perform lower on standardized tests than their Englishspeaking counterparts and they are less likely to complete high school or receive an equivalent degree (Ruiz-de-Velasco and Fix 2000).

Second, schools struggle to assist ELs to master academic language and skills required to reclassify as fluent English proficient (RFEP). In 2010-2011, California schools reclassified only $11.4 \%$ of ELs (CDE 2011a). Moreover, a significant portion of ELs are not reclassified for 5-6 or more years, resulting in long-term status for the majority of secondary ELs. Callahan (2005) found $68 \%$ of seventh- to twelfth-grade ELs who took the California English Language Development Test (CELDT) in 2003 reported enrollment in California schools for 7 years or more. Flores et al. (2009) found that nearly a third (29\%) of ELs were not reclassified by

\footnotetext{
${ }^{1}$ I calculated California's share of U.S. K-12 ELs using Ed.gov's Ed Data Express: Data About Elementary and Secondary Schools in the U.S. interactive tool (http://eddataexpress.ed.gov/dataelements.cfm). I calculated this percentage by dividing the number of K-12 California ELs by the total number of U.S. K-12 ELs reported by states in 2010-11. I selected the following options to obtain the numbers: Graphs and Tables; Title III Program-English Learners, English Learners-Facts and Figures; All English Learners: 2010-11.
} 
eighth grade in the Los Angeles Unified School District (LAUSD). Three quarters of these non-reclassified students had been in the district more than 8 years. Similarly, Olsen (2010) reported that across 40 California districts, $59 \%$ of secondary school ELs were long term; in 13 of these districts, $75 \%$ of secondary ELs were long term. No national data exist on the number of long-term ELs, yet the available evidence suggests that the problem is widespread (Freeman and Freeman 2002; Menken et al. 2012; Ruiz-de-Velasco and Fix 2000).

In California and in the United States as a whole, another indicator of our system's failure to support adequate progress, despite enrollment in US schools, is that ELs are increasingly US born rather than foreign born. In California, the estimate of US-born secondary school ELs is $49 \%$, while nationwide the estimate is $57 \%$ (Capps et al. 2005; Batalova et al. 2007). In LAUSD, $73 \%$ of ELs who had not been reclassified by eighth grade were US born (Flores et al. 2009).

Third, EL programs lack statewide consistency due in great part to the CDE's practice of providing districts leeway in interpreting its guidelines regarding the identification, classification, reclassification, and monitoring of ELs, program placement, curriculum, and instruction (Abedi 2008; Kolesch et al. 2010; Parrish et al. 2006; Linquanti 2001). For ELs with less than "reasonable fluency in English," state policy calls for placement in a Structured English Immersion/ Sheltered Immersion classroom (CDE 2006). ${ }^{2}$ These classes are to include both English language development (ELD) appropriate to students' levels of English proficiency and content instruction using specially designed academic instruction in English (SDAIE), as needed, to provide full access to the core curriculum; they may also include primary language support. Yet districts have discretion to define "reasonable fluency" to determine the appropriate amount of ELD and to select from a broad range of curricula. Some of these curricula provide access to core English language arts (ELA), others provide ELD, but not access to the core, and others provide primarily remediation. Similarly, districts define reclassification criteria within state guidelines. Districts, in turn, allow schools discretion in interpreting their guidelines, leading to different policies, programs, and practices at the school level (Kolesch et al. 2010; Parrish et al. 2006; Olsen 2010; Working Group on ELL Policy 2010; Linquanti and Cook 2013).

Although a few larger scale studies have provided broad outlines of variation in EL policies and programs and identified school practices associated with greater EL success (Parrish et al. 2006; Williams et al. 2007), we have much to learn about variation and features of EL curricular programs at the school level, where ultimately staff decide how to provide ELD and access to the core. Nor do we know how characteristics of EL curricular programs co-vary with school cultures and practices and EL outcomes. In particular, there is a paucity of data on EL Curricular Streams, which I conceptualize as the whole of the patterned sets of ELD, content, and intervention courses, EL and non-El participation in these courses, and policies and practices regarding entry, placement, and exit criteria. Conceived to represent the complexity of EL programs designed to meet legal mandates for providing both

\footnotetext{
${ }^{2}$ In 1998 the passage of Proposition 227 in California required that public schools instruct all students overwhelmingly in English, unless school and parental waivers are sought and approved.
} 
ELD and access to the core curriculum, the concept of Curricular Streams goes beyond tracking which focuses primarily on student assignment to sets of courses based on ability in one or more content areas (Oakes 1990). By instantiating school staff decisions about how to provide ELD and access to the core, Curricular Streams, constitute the heart of EL programs. They comprise the structure for delivering an ostensibly coherent set of curricular and instructional experiences to address the dual goals of attaining English Language Proficiency (ELP) and gradelevel achievement. School-level descriptions and mapping of Curricular Streams simultaneously portrays not only the sets of courses, but also other key elements (e.g., entry, placement, and exit criteria), thus revealing schools' programmatic emphases and exposing them to analysis. They can help us answer questions such as: To what extent do different Curricular Streams provide ELD instruction and access to the core and full curriculum? What is the relative emphasis of different EL Curricular Streams on developing ELP versus core academic content mastery? Remediating versus accelerating? Isolating versus integrating ELs?

Moreover, analyzing the extent to which different Curricular Streams provide ELD and access to the core is critical because criteria for reclassifying as fluent English proficient include threshold levels of performance on state tests of both ELP and core ELA content standards (and in some districts mathematics as well). Without ELD instruction and access to the core, meeting such criteria is enormously challenging for ELs. Consequently, these students are more likely to become longterm ELs for whom it becomes increasingly difficult to reclassify as fluent English proficient (Linquanti 2001; Valdés 2001; Olsen 2010).

For these reasons, school-level descriptions and analysis of EL Curricular Streams and the school cultures and practices with which they co-occur are critical. Given the limited body of knowledge, case studies, which garner rich, nuanced description, hypothesis generation, and grounded theory building, are especially appropriate (Yin 1989). Embedded within a larger investigation of the education of ELs in California's middle schools (Kolesch et al. 2010), this work complements and informs previous research by detailing and providing a comparative analysis of EL Curricular Streams in four middle schools, situating them within the broader culture and practices of their schools, and generating implications for research, policy, and practice and hypotheses about characteristics that might increase EL opportunity to learn and meet the dual goals of attaining ELP and grade-level achievement.

\section{Background and Context}

\section{Middle School: A Pivotal Juncture in Schooling}

Middle school is a pivotal juncture for setting students on trajectories towards school engagement or disengagement and corresponding possibilities for fulfilling or dwindling futures (Carnegie Corporation of New York 1989; Eccles 2008; Eccles et al. 1984; Estrada 1996; Williams et al. 2010). Eccles and others have argued convincingly that declines typically observed in student motivation, engagement, and achievement during middle school are not inevitable; rather a loss in students' 
confidence in their ability to do well and lack of developmentally appropriate educational and social environments appear to be key (Eccles 2008; Eccles and Midgley 1989; Eccles et al. 1993). In particular, Eccles points to schools' role in creating failure experiences and fostering a sense of incompetence and lack of autonomy and belongingness (Eccles 2008). Significantly, achievement and engagement in middle school strongly predict achievement and graduation from high school (Eccles 2008; Kurlaender et al. 2008; Rumberger and Lim 2008). For ELs, who face additional linguistic and academic challenges, middle school may be our last best hope for promoting retention and success.

\section{English Learner Access to Core Content Curriculum}

Research indicates that access to a coherent instructional and curricular program aligned with state standards is key to improving education for ELs (Parrish et al. 2006; Williams et al. 2007). A number of studies show that when students do not have access to the core standards-based curriculum, instruction often lacks linguistic and academic rigor, opportunity to learn diminishes, and students often fall further behind (Hallinan and Kubitschek 1999; Oakes 1990; Oakes and Lipton 1999; Olsen 1997; Valenzuela 1999). Unfortunately, until reaching early advanced or advanced levels of ELP, EL access to the core is often limited or delayed by placement in modified or remedial instruction or low mainstream tracks at the secondary level (Callahan 2005; Olsen 2010). This practice is based on the assumption that students cannot profit from instruction in core content until they are English proficient (Valdés 2001). Yet, isolation from English speakers in formal and informal school settings impedes both English proficiency and academic development (Carhill et al. 2008; Valdés 2001). Consistent with previous research (Hallinan 1994; Hallinan and Kubitschek 1999), Callahan (2005) reported that track placement was a better predictor of academic performance than proficiency in English.

Recent studies of the effects of English-as-a-Second-Language (ESL) placement on core course taking have yielded mixed results, yet they point to timely access to the core as key to academic outcomes and indicate that continuing EL status may restrict access. In one study, Callahan et al. (2009) found the effect of ESL placement for immigrant students varied by generational status and level of immigrant concentration within secondary schools. In high-immigrant-concentration schools, the effect of ESL versus mainstream placement was positive on Algebra II, chemistry, and college prep course enrollment as well as on junior year GPA, primarily for second-generation students. In low-concentration schools, the effect of ESL placement was negative on math, science, and college prep enrollment, primarily for first-generation students. The authors hypothesized that in low-concentration schools first-generation students might experience limited course options whereas in high-concentration schools, second-generation students might benefit from exposure to first-generation students and that ESL placement might provide access to instruction to overcome a variety of challenges. However, in a second study, Callahan et al. (2010) reported that for Generation 1.5 or 2 secondary ELs with greater ELP and more years in US schools, ESL placement negatively affected math, science, and social science college prep enrollment, math 
achievement, and cumulative GPA. ESL course placement positively affected math outcomes only for recent immigrants with relatively low self-reported ELP. Consequently, the authors recommended caution in ESL placement and retention. For grade 6 ELs, Kim and Herman (2010) found that, compared with those who reclassified at lower ELP levels, ELs who reclassified with the highest ELP criterion showed significantly slower learning rates in math subsequently. They suggested that continuing EL status might have restricted these students' access to core math, which builds prior knowledge for the more advanced math courses necessary for high school graduation and post-secondary education.

\section{English Learner Access to English Language Development Instruction}

Key research-based guidelines for ELD instruction indicate a need for a daily dedicated block that: emphasizes listening and oral language, although it can incorporate reading and writing; explicitly teaches elements (e.g., forms and functions) of English, while integrating meaning to support explicit instruction; and emphasizes academic language as well as conversational language (Dutro and Kinsella 2010; Saunders and Goldenberg 2010; Saunders et al. 2013). Two other guidelines are particularly salient to this study. The first is that ELD instruction should continue through at least early advanced levels of ELP and that it requires increasing focus on academic language. This guideline is especially relevant for Californian's middle school ELs, more than half of whom score at early advanced and advanced levels of ELP (52 \% for 2011-2012; CDE 2013). These authors hypothesize (and report observing) that lack of ELD instruction beyond intermediate levels of ELP may be one reason for the plateau effect resulting from typically rapid progression to intermediate levels then slow progression to early advanced and advanced levels of ELP (Genesee et al. 2006). Moreover, Dutro and Kinsella point out that secondary curricular placement policies often result in a mixture of long-term ELs and newcomers in the same classroom, yet meeting their very different ELD needs is challenging. Finally, they rue the increasingly common practice of substituting ELD instruction with remedial reading interventions that are not intended to provide explicit instruction in English for everyday and academic purposes.

The second particularly salient guideline is that ELs should be grouped in heterogeneous ability classrooms during most of the day and grouped by ELP levels specifically for ELD instruction. Saunders and his colleagues base this guideline on syntheses of research indicating that homogenous classrooms lower achievement among lower achieving students, while not benefitting average and higher achieving students (Slavin 1987, 1989). Moreover, regrouping within heterogeneous classrooms can occur productively when teachers tailor instruction to student levels in specific subjects, assess frequently, and regroup as needed.

\section{Effective School Cultures and Practices for English Learners}

Some authors have suggested that an "effective schools" culture, including a school-wide focus on achievement, is key to the success of English learner programs, even those implementing best guidelines (Aguila 2010; Parrish et al. 
2006; Williams et al. 2007). This idea is bolstered by the consistency between the broader cultures and practices of schools that beat the odds with ELs and those found in the effective schools literature (Bryk 2010; Bryk et al. 2010; Parrish et al. 2006; Williams et al. 2007). Williams et al. (2007) for example found that among California elementary schools serving similar proportions of low-income ELs, four broad effective school practices distinguished schools producing higher achievement that met the statewide target for all students: (a) district and principal leadership in using student assessment data to improve instructional practices and student achievement; (b) quality instructional resources, particularly teachers with strong content and curricular knowledge who could raise student achievement, map standards to teaching, and use data to inform instruction; (c) implementation of a coherent, standards-based curriculum and instructional program within and between grades; and (d) prioritizing student achievement by using measurable and monitored objectives. Three other practices were also positively correlated, though not as strongly: (a) establishing and enforcing high expectations for student behavior, (b) involving and supporting parents, and (c) teacher collaboration.

A number of other qualitative and quantitative studies point to school practices and policies that appear to matter for ELs' success and are consonant with these broader findings. For example, recent research indicates that the roles and responsibility teachers assume for ELs' achievement affect students' class participation and roles. Yoon (2008) found that secondary teachers who positioned themselves as teachers of all children (vs. as content teachers of "regular" students) and who viewed ELs as essential contributors to classroom learning, elicited more engaged participation from ELs, which positioned them as powerful rather than powerless.

\section{Context of the Investigation}

The four cases were part of Phase 2 of a 2-year investigation of the education of EL students in California's public middle schools. During Phase 1, researchers documented the overall landscape of EL programs in 64 middle schools selected to represent high and low EL concentrations, within 13 districts with among the highest percentage of ELs in the state (Kolesch et al. 2010). Researchers defined the cut point for high versus low concentration as $28 \%$, which was the median for all 319 middle schools in the 25 high-concentration EL districts that made up the initial pool of districts that researchers invited to participate. ${ }^{3}$ District- and school-level questionnaires and interviews of staff knowledgeable about EL instructional practices gathered data regarding instructional programs, instructional support

\footnotetext{
3 To select the pool of 25 districts, researchers identified the 50 districts that educated $52 \%$ of ELs in California. Of these, researchers included the 13 districts that educated $32 \%$ of ELs and 12 districts more, which they randomly selected from the remaining 37 districts. Of the 319 schools in the 25 districts, a random sample of 75 low-EL and 75 high-EL concentration schools were targeted to participate. Ultimately 64 middle schools in 13 districts participated in Phase 1 . The 13 districts educated $30 \%$ of the ELs in California and had an average EL concentration similar to the pool of 25 districts (34\% versus $36 \%$ ). Similarly, the 64 schools had an average EL concentration similar to that of the 150 schools originally targeted for participation (29\% versus $28 \%$ ).
} 
practices, and capacity to educate middle school ELs. Phase 1 findings indicated wide variation in districts' interpretation and implementation of state policies for ELs, and similarly, variation in schools' interpretation and implementation of district policies. Consequently, variation characterized California middle school EL programs and many schools struggled to meet students' needs. Phase 2 used casestudy methods to unpack this variation within a subsample of middle schools identified as having promising practices.

\section{Research Focus}

This article describes and provides a comparative analysis of the Curricular Streams of four middle schools centering on: (a) the extent to which they provided ELD instruction and access to the core and full curriculum; (b) the relative emphasis on ELP versus core academic content, remediation versus acceleration, and isolation versus integration of ELs with non-EL peers; and (c) the broader school cultures and practices, focusing on leadership, distributed responsibility, and prioritizing achievement for ELs. I provide implications for research, policy, and practice and hypotheses about the characteristics of Curricular Streams and school cultures that might increase ELs' opportunity to learn and meet the dual goals of attaining ELP and grade-level achievement.

\section{Method}

\section{Case Study Sample Selection}

Researchers generated an initial pool of 14 schools from the 13 Phase 1 districts in two ways: (a) Phase 1 district- or school-level participant nomination of middle schools with promising EL practices for which they could provide "plausible evidence" such as achievement, program evaluation, or formative assessment data, and (b) EL student performance above the median on the California Standards Test of English language arts (CST-ELA). Schools were also selected to represent high and low concentrations of ELs because Phase I findings indicated that districts struggled with implementation of EL policies in these contexts. One district decided to cease participating, which eliminated two schools. After 1-day visits that included classroom observations and brief interviews with staff in the 12 remaining schools, researchers reviewed summaries of observations, interviews, as well as EL performance on the CST-ELA, CELDT, and reclassification rates. Researchers selected for more in-depth case study the seven schools that showed the most promise. The schools represented a range of EL concentrations (3.2-46\%), with an average EL concentration in Phase $2(28 \%)$ similar to that of the 64 schools that participated in Phase 1 (24\%). This report presents findings from four of the seven schools in which the author was the lead researcher. EL concentration ranged from $3.2 \%$ (very low) to $38.5 \%$ (high); two schools had a little below average concentrations (12.1 and 15.4 vs. $17 \%$ ) for California middle schools. 
Participants

\section{Researchers}

All five researchers were former teachers. The author's work centers on classroombased educational research (with some professional development) on effective pedagogy and achievement in culturally and linguistically diverse contexts and EL linguistic, instructional, and curricular policies and practices. For the four other researchers, who were also former instructional coaches and/or administrators, this position represented a shift from their primary work of providing teacher professional development on increasing ELs' English language and literacy in the content areas. Thus, for all, the researcher position was grounded in experiences with schools, classrooms, and teachers via multiple filters and familiarity with the opportunities and challenges of educating English learners.

\section{School Staff}

Administrators and English learner coordinators were aware that their schools had been selected due to indicators of promising practices. Systematic demographic, educational background, and teaching experience data were not gathered from school staff. Nonetheless, staff often conveyed information about the number of years they had been in their positions or the number of years they had been teaching particular courses. This information suggested that most were seasoned professionals with the exception of two newly hired assistant principals.

\section{Procedure}

School site visits occurred from April to June. During the initial 1-day visit, two to three researchers conducted brief interviews with principals (or academic vice principals), EL coordinators, and teachers. Researchers observed ELD/ELA and content classes, including ELD content, SDAIE, sheltered, and mainstream content classes with EL enrollment. During the follow-up 2-day visits, two to three researchers conducted more in-depth interviews with school staff and observed these same types of classes again. The lead researcher worked with the EL coordinator who created the observation schedules. In every school, several relevant classes were deemed off limits due variously to uncooperative teachers or poor teaching; this phenomenon did not seem to vary systematically by school, however. Researchers recorded interviews and observations primarily on laptops. Handwritten notes were transferred to laptops.

\section{Data Sources}

\section{California Department of Education DataQuest}

Demographic Data The CDE's DataQuest website, which provides data on every public school and district in California, was the source of all demographic data. I 
gathered enrollment, grade levels, percent eligible for free and reduced meals, ethnic distribution, percent ELs, percent of ELs at beginning to advanced levels of ELP, and languages spoken. I estimated the percent of newcomers in each school by dividing the number of ELs who took the initial CELDT assessment by the total number of ELs tested with the CELDT (number of initial/number of initial plus annual assessments).

California (Achievement) Standards Tests (CSTs) The state runs the Standardized Testing and Reporting (STAR) program and posts the results on its DataQuest website. Central to the program are the CSTs, criterion-referenced tests administered each spring to grades 2 through 11 to assess academic achievement aligned with grade-level content standards in ELA, math, and other subjects. ELs take the CSTs in English if they have been in school 12 months or more. Scale scores for all content areas range from 150 to 600 , and performance-level scores vary slightly by area and grade (CDE 2009a). CST-ELA performance levels are: Far Below Basic (FBB), approximately 3 years below grade level (150-267 for grade 6; 150-262 for grade 7; 150-265 for grade 8); Below Basic (BB), approximately 2 years below grade level (268-299 for grade 6; 263-299 for grade 7; 266-299 for grade 8; Basic, approximately 1 year below grade level (300-349 for grades 6 through 8); Proficient, grade level (350-393 for grade 6; 350-400 for grade 7; 350-394 for grade 8); and Advanced, above grade level (394-600 for grade 6; 401-600 for grade 7; 395-600 for grade 8). The CDE requires performance on the CST-ELA to be used as a basic skills criterion for reclassification to fluent English proficient (CDE 2008). It considers scores in the range of Basic to mid-Basic (300-324) as indicating that students may be sufficiently proficient to participate in the mainstream curriculum and directs districts to select a cut point in this range.

Academic Performance Index (API) The CDE calculates the API, an aggregate measure of schools' performance based primarily on CST scores, with scores ranging from 200 to 1,000 (CDE 2009c). Until schools reach the target score of 800, the state sets annual growth targets, schoolwide and for subgroups, including ELs. After reaching an API of 800 schoolwide, schools must maintain that level of achievement and continue to improve the academic performance of all subgroups of students. Based on the API, the state ranks schools into deciles, within type (elementary, middle, and high school). It also ranks schools from 1 to 10 based on 100 similar schools based on student mobility, ethnicity, socioeconomic status, percent of teachers who hold full and emergency credentials, percent of ELs, percent of RFEP students, percent of gifted and talented students (GATE), and other similar factors.

Adequate Yearly Progress (AYP) To meet federal accountability requirements under the No Child Left Behind Act of 2001 (2002), schools must meet AYP goals for all student subgroups (CDE 2009b). Following federal guidelines, for each school states set yearly absolute targets for the proportion of students who must score proficient on state tests of achievement to ensure that all students reach 
proficiency by 2014. Thus, unlike the API, the AYP does not set annual growth goals based on individual schools' baseline performances. Rather, it establishes a specific bar that all subgroups within schools must attain to meet AYP.

California English Language Development Test (CELDT) California's State Department of Education mandates the administration of the CELDT at school entry to all students who have a home language other than English. The state labels as ELs students whose performance fails to meet the criterion for English proficiency and schools test them on a yearly basis thereafter, until students are reclassified as fluent English language proficient (CDE 2009d). The CELDT assesses listening, speaking, reading, and writing in grades K-12. (Prior to 2009-2010, K-1 students were tested in listening and listening only.) The state defines the timeline for testing (late summer through October), controls the scoring and classification of students (Beginning, Early Intermediate, Intermediate, Early Advanced, and Advanced English proficient), and the reporting of scores to districts (late January to early February). Students meet the CELDT criterion for English proficiency when they score at Early Advanced or higher on average across domains, with no subscore below Intermediate. The CDE requires schools to use the CELDT criterion as the primary ELP criterion for reclassification.

\section{Administrator, EL Coordinator, and Teacher Interviews}

Policies and Practices Regarding EL Identification, Classification, Curricular Placement, and Reclassification EL coordinators and school, district website, and CDE documents were the primary sources for these data. The interview queried EL coordinators about EL demographics (e.g., number, distribution of English proficiency levels), processes for EL identification, classification, and curricular placement, and processes and specific criteria for reclassification. The CDE requires districts to use four criteria for reclassification: ELP (primarily meeting the CELDT criterion); performance in basic skills (primarily CST-ELA performance); teacher evaluation of students' curriculum mastery; and parental opinion. Yet, a statewide local control policy provides districts discretion to set CST cut points and add performance criteria.

Curricular Streams Across the four schools, researchers queried three principals, three academic vice principals, four EL coordinators (three of whom were also teachers), and 39 teachers (11 in one school, 10 in two of the schools, and eight in the only school with a grades 7-8 configuration) regarding the Curricular Streams in the school, including EL-specific, intervention, mainstream, GATE, and other streams specific to the schools. For each, researchers gathered information regarding (a) number of ELs; (b) criteria for entry, placement, and exit (e.g., ELP levels, CST scores; number of years in EL status); (c) ELD, content, and intervention courses; (d) extent of EL and non-EL student participation; and (e) the fluidity of movement between them. To gage access to the core further, researchers asked teachers and EL coordinators about the specific curricula they used, the extent to which it aligned 
with grade-level content standards, and about any adaptations they made to provide access to the core. Researchers also asked these staff about the relative emphasis on developing ELP for reclassification to fluent English proficient versus providing access to grade-level academic content and developing the skills for success in core courses as well as benchmark and state assessments. EL coordinators reported the number of students in each stream, based on current enrollments at the time of site visitations. ${ }^{4}$

School Culture, Including Leadership, Distributed Responsibility, and Prioritizing EL Achievement Researchers asked principals to describe their schools, including type (neighborhood, magnet) demographics, and routes for entry. Interview questions queried principals, EL coordinators, and teachers about aspects of EL instructional practices that were going well, those that needed work, and how the school assisted EL coordinators and teachers to develop effective instruction for ELs. Researchers also queried these staff about the extent to which teachers were aware of student performance in their classrooms as well as on state and district assessments, and the extent to which such knowledge informed instructional practice.

\section{Classroom Observations}

Initial 1-day as well as follow-up observations included English Language Development/English language arts (ELD/ELA), reading interventions, ELD, sheltered, and SDAIE core content classes, as well as mainstream core content classes with EL enrollment. Researchers observed classrooms at least two to three times; classrooms with high levels of teacher and student engagement received three to four observations due to the project's overall focus on promising practices. Full period observations (about $50 \mathrm{~min}$ ) nearly always preceded teacher interviews. Live running observations recorded as much detail as possible about the lesson, including content area, curricular materials, task activity, teacher-student interaction and peer interaction. Also noted were teacher and student engagement and the extent to which activities were organized, productive, as well as content and grade appropriate. Researchers recorded classroom demographics with the assistance of the teacher (total number of students, number of ELs, reclassified students, and any other designated students). These observations anchored teacher interview responses in actual practice. (They also provided data about the nature of teaching and learning; analysis of those data is beyond the scope of this paper.)

\footnotetext{
${ }^{4}$ Discrepancies in EL coordinator-reported and state DataQuest-reported number and percentage of ELs in any particular category likely reflect different timing. For example, the CELDT testing window is July 1-October 31; CELDT results reach schools in late January or February; and the language census data, which collects background and programmatic data on ELs is due to the state in late March. By the time of site visits in late spring, EL populations in schools had experienced much transiency.
} 


\section{Data Analysis}

Data sources triangulated information gathered in several ways: First, the interviews used a common set of questions across different types of school staff (i.e., administrators, EL coordinators, and teachers). Second, the interviews used a different set of common questions within the same type of staff (e.g., teachers). Third, observations of classrooms provided a window into actual practices that could verify school staff self-reports. Fourth, researchers gathered supporting documents, such as reclassification criteria, and classroom artifacts. Finally, researchers gathered demographic, performance, and EL data from the school, but relied on the CDE's DataQuest website for verification.

Data analysis was descriptive and comparative. Interpretations were anchored in data triangulated by staff interviews, classroom observations, school and district

Table 1 Analytic categories and data sources for english learner Curricular Streams and School Culture

\begin{tabular}{llllll}
\hline Categories of analysis & \multicolumn{5}{l}{ Data sources } \\
\cline { 2 - 6 } & Administrator & District and & EL & Teacher & Classroom \\
& interviews & school & coordinator & interviews & observations \\
& $(6 / 7)$ & documents & interviews & $(29 / 53)$ & $(49 / 94)$ \\
& & (NA) & $(4 / 7)$ & & \\
\hline
\end{tabular}

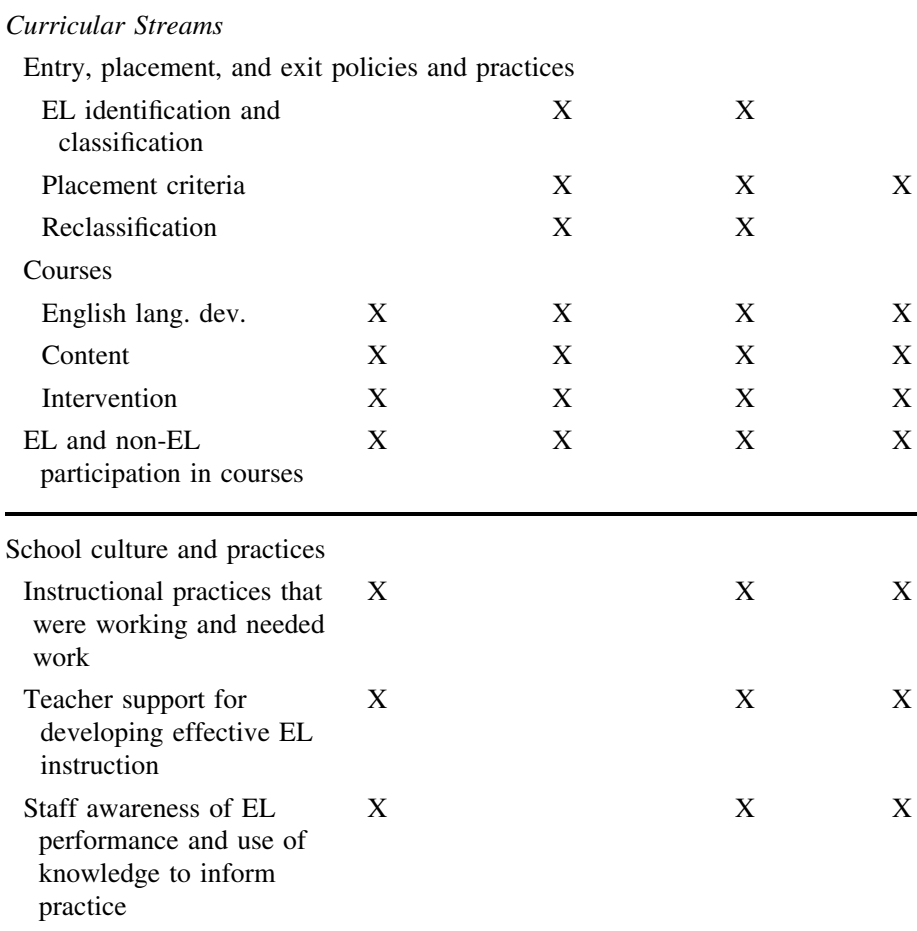

Numbers in parentheses indicate number of interviewees/number of interviews or number of classrooms/ number of classroom observations. All teachers interviewed were also observed. The schedule did not permit every classroom teacher observed to be interviewed 
documents, and objective data from state sources (Miles and Huberman 1984). I gathered all site researchers' interview transcripts and running classroom observations as well as summaries, documents, and artifacts. The analytic categories of interest pertaining to Curricular Streams, included: (a) entry, placement, and exit policies and practices including those involving EL identification, classification, and reclassification and those specific to placement within streams; (b) ELD, content, and intervention courses; and (c) extent of EL and non-EL participation in these courses. Analytic categories pertaining to school culture and practices included: (a) instructional practices that were working and needed work; (b) teacher support for developing effective EL instruction; and (c) staff awareness of EL performance and use of knowledge to inform practice (see Table 1). To analyze each category within cases, I used an iterative process that involved creating tables that arrayed data from all sources and noting patterns mentally and in writing. When evidence of a pattern appeared in one set of data, I looked for confirming or disconfirming evidence across multiple sources and modified my interpretations, accordingly. I returned repeatedly to the original data sources. Next, I developed written descriptions of each case and graphic representations of the Curricular Streams. These descriptions and graphic representations facilitated comparative analysis across the same categories, which followed a similar iterative process.

\section{The Four Case Study Schools}

\section{Cove Middle School}

Cove Middle School (CMS), an International Baccalaureate (IB) school, situated in the heart of a large, urban district, served a poor, inner-city population of primarily Latino students $(81.7 \%) ; 84 \%$ of its students were eligible for free and reducedprice meals (see Table 2). The principal described it as a neighborhood school that was often "not chosen" in a district with open enrollment. ELs represented $38.5 \%$ of its population and $91.9 \%$ were Spanish speaking (see Table 2). Twenty-six percent of ELs were at Beginning or Early Intermediate levels of ELP, $35 \%$ were at the Intermediate level and $39 \%$ were at Early Advanced or Advanced levels (see Table 3). In 2008-2009, CMS' reclassification rate of $12.2 \%$ surpassed the district $(10.2 \%)$ and state averages $(10.8 \%)$ (see Table 4$)$. After losing ground the year before, in 2008-2009 CMS met its API growth target for all groups, moving 17 points from an overall API of 642 to 659 (see Table 4). The 2-year data (2007-2009) showed a schoolwide API net growth of 15 points and an EL-API net growth of 3 points. CMS did not meet its AYP schoolwide nor for any subgroups in 2007-2008 or 2008-2009. With a state rank of 2 and similar school rank of 2, CMS remained well below the median of similar schools.

\section{Knoll Middle School}

In the same district as CMS, Knoll Middle School (KMS) was a National Blue Ribbon School of Excellence and a visual and performing arts magnet school situated in an upscale neighborhood. It served a diverse mix of primarily white 
Table 2 Demographics of four case study middle schools

\begin{tabular}{|c|c|c|c|c|}
\hline Demographics & Cove MS & Knoll MS & Dell MS & Interior MS \\
\hline \multicolumn{5}{|l|}{ School characteristics } \\
\hline Grade levels & $6-8$ & $6-8$ & $6-8$ & $7-8$ \\
\hline Enrollment & 871 & 1,289 & 2,278 & 641 \\
\hline Free and red. lunch & 84.2 & 34.1 & 37.1 & 67.7 \\
\hline English learners & 38.5 & 12.1 & 3.2 & 15.4 \\
\hline Newcomers & 5.4 & 5.9 & 28 & 6.8 \\
\hline \multicolumn{5}{|l|}{ Ethnic distribution } \\
\hline White & 6.9 & 43.3 & 34.5 & 22.5 \\
\hline Latino & 81.7 & 39.4 & 33.2 & 34.6 \\
\hline African American & 2.1 & 3.2 & 6.5 & 23.9 \\
\hline Asian & 4.8 & 10.0 & 17.7 & 15.9 \\
\hline Other & 4.5 & 4.1 & 8.1 & 3.1 \\
\hline \multicolumn{5}{|c|}{ English learner languages $^{\mathrm{a}}$} \\
\hline Spanish & 91.9 & 89.1 & 65.8 & 58.6 \\
\hline Arabic & & & 4.1 & \\
\hline Armenian & & & 6.8 & \\
\hline Cantonese & & & & 4.0 \\
\hline Farsi & & & 4.1 & \\
\hline Hmong & & & & 18.2 \\
\hline Korean & & & 4.1 & \\
\hline Mien (Yao) & & & & 8.1 \\
\hline Russian & & & 4.1 & \\
\hline Other & 8.1 & 10.9 & 11.0 & 11.1 \\
\hline
\end{tabular}

All numbers except grade levels and enrollment represent percents. Data are for 2008-2009. Source California Department of Education (2010)

a Language groups with $4 \%$ or higher representation are reported

Table 3 Percent of ELs at CELDT English language proficiency levels at four case study middle schools

\begin{tabular}{lcccc}
\hline ELP levels & Cove MS & Knoll MS & Dell MS & Interior MS \\
\hline Advanced & $9(30)$ & $8(16)$ & $7(6)$ & $18(23)$ \\
Early adv. & $30(107)$ & $31(59)$ & $51(46)$ & $44(54)$ \\
Intermediate & $35(124)$ & $37(72)$ & $30(27)$ & $22(27)$ \\
Early intermed. & $16(57)$ & $19(36)$ & $10(9)$ & $11(14)$ \\
Beginning & $10(34)$ & $5(10)$ & $2(2)$ & $5(6)$ \\
\hline
\end{tabular}

Based on annual CELDT assessment. Number of students in parentheses. Data are for 2008-2009. Source California Department of Education (2010)

(43.3 \%) and Latino students (39.4\%); $34.1 \%$ of its students were eligible for free and reduced-price meals (see Table 2). As a magnet school, it drew $40 \%$ of its student population from the wider district and the remaining students from the neighborhood. Part of a district that is under voluntary desegregation, KMS 
Table 4 Performance data of four case study middle schools

\begin{tabular}{|c|c|c|c|c|}
\hline Performance measure & Cove MS & Knoll MS & Dell MS & Interior MS \\
\hline \multicolumn{5}{|l|}{ Schoolwide } \\
\hline API 2009 & 659 & 810 & 844 & 772 \\
\hline API target met $2009^{\mathrm{a}}$ & Yes & Yes & Yes & Yes \\
\hline API statewide rank 2009 & 2 & 7 & 9 & 6 \\
\hline API similar schools rank 2009 & 2 & 2 & 1 & 8 \\
\hline API growth 2008-2009 & $17^{\mathrm{b}}$ & 0 & -2 & $30^{\mathrm{b}}$ \\
\hline API growth 2007-2008 & -2 & $-1^{\mathrm{a}}$ & $12^{\mathrm{a}}$ & $41^{\mathrm{b}}$ \\
\hline \multicolumn{5}{|l|}{ English learner } \\
\hline API ELs 2009 & 597 & 660 & NA & NA \\
\hline API target met 2009 & Yes & No & NA & NA \\
\hline API growth 2008-2009 & $18^{\mathrm{b}}$ & -8 & NA & NA \\
\hline API growth 2007-2008 & -15 & $17^{\mathrm{b}}$ & 2 & $11^{\mathrm{b}}$ \\
\hline 2009 API target & Yes & No & NA & NA \\
\hline School reclassification rate ${ }^{c}$ & 12.2 & 27.6 & 31.1 & 18.3 \\
\hline District reclassification rate ${ }^{c}$ & 10.2 & 10.2 & 14.8 & 8.8 \\
\hline
\end{tabular}

NA denotes not applicable; comparable data for 2008-2009 were unavailable because the number of ELs participating in statewide testing fell just below the cut off for reporting. Source: California Department of Education (2010)

${ }^{\text {a }}$ Schoolwide API growth targets are not applicable after reaching 800

b This gain met API growth targets

${ }^{c}$ Reported in percent. State reclassification rate was $10.8 \%$

conducted recruitment tours in January and February in advance of school choice deadlines. Most of the Latino students had chosen KMS through this process and were bussed from other neighborhoods. ELs represented $12.1 \%$ of its population and $89.1 \%$ were Spanish speaking (see Table 2). Twenty-four percent of ELs were at Beginning or Early Intermediate levels of ELP, $37 \%$ were at the Intermediate level and $39 \%$ were at Early Advanced or Advanced levels (see Table 3). In 2008-2009, KMS' reclassification rate of $27.6 \%$ surpassed the district (10.2\%) and state averages (10.8\%) by far (see Table 4). KMS' schoolwide API of 810 was above the state target of 800; over 2 years (2007-2009), it showed a net schoolwide API loss of -1 and an EL-API net gain of 9 (see Table 4). In 2008-2009, KMS met API growth targets only for whites and Asians. Although KMS had a statewide rank of 7, it ranked 2 compared to similar schools. Finally, KMS did not meet its AYP targets in 2007-2008 or 2008-2009.

\section{Dell Middle School}

Dell Middle School (DMS) situated in a middle-class neighborhood of a large, urban district served a diverse mix of primarily white (34.5\%), Latino (33.2\%), and Asian (17.7\%) students; $37.1 \%$ of its students were eligible for free and 
reduced lunch (see Table 2). With a large population of 2,278 students, DMS had three schools within a school: a gifted and talented school for advanced studies (SAS), a math/science/technology magnet, and a neighborhood school. Consequently, it drew many of its students from the wider district lottery of those seeking enrollment. ELs represented only $3.2 \%$ of its population and were more diverse than at other schools: $65.8 \%$ spoke Spanish, $6.8 \%$ spoke Armenian; $4.1 \%$ spoke each of the following Arabic, Farsi, Korean, and Russian (see Table 2). Twelve percent of ELs were at Beginning or Early Intermediate levels of ELP, $30 \%$ were at the Intermediate level and $58 \%$ were at Early Advanced or Advanced levels (see Table 3 ). It was the only school with a high proportion of newcomers (28\%) due to its location in a metropolitan area with high concentrations of immigrants. In 2008-2009, DMS' reclassification rate of 31.1\% surpassed the district (14.8\%) and state averages (10.8\%) by far (see Table 4). DMS' 2008-2009 schoolwide API of 844 was above the state target of 800 . In the 2-year period 2007-2009, it showed a net API gain of 10 points schoolwide, but it did not meet growth targets for several subgroups (see Table 4). In 2007-2008 EL-API grew by 2 points, which did not meet the growth target. Comparable data for 2008-2009 were unavailable because the number of ELs participating in statewide testing fell just below the cut off for reporting. It did not meet AYP targets in 2007-2008 or 2008-2009. Finally, although DMS had a statewide rank of 9, it ranked 1 compared to similar schools.

\section{Interior Middle School}

Interior Middle School (IMS) had the only grade 7-8 configuration and the smallest student population (641). Situated in an upscale neighborhood of a large, urban district, it served a diverse mix of primarily Latino (34.6\%), African American $(23.9 \%)$ white $(22.5 \%)$, and Asian students (15.9\%); $67.7 \%$ of its students were eligible for free- and reduced-price meals (see Table 2). According to staff, the neighborhood children tended not to attend IMS. ELs represented $15.4 \%$ of its population and were more diverse than in California as a whole: $58.6 \%$ spoke Spanish, $18.2 \%$ spoke Hmong; and $8 \%$ spoke Mien (see Table 2). Sixteen percent of ELs were at Beginning or Early Intermediate levels of ELP, $22 \%$ were at the Intermediate level and $62 \%$ were at Early Advanced or Advanced levels (see Table 3). In 2008-2009, IMS' reclassification rate of $18.3 \%$ surpassed the district $(8.8 \%)$ and state averages $(10.8 \%)$ by far (see Table 4$)$. Although it had been in PI status for 5 years, IMS was now a rising school, posting consecutive schoolwide API gains of 41 and 30 points in 2007-2008 and 2008-2009 respectively (see Table 4). In 2007-2008 EL-API grew by 11 points; unfortunately comparable data for 2008-2009 were unavailable because the number of ELs participating in statewide testing fell just below the cut off for reporting. Nonetheless, in both years, it met API growth targets schoolwide and for all subgroups. With a 2008-2009 API of 772, IMS was closing in on the state target of 800. It had a statewide API rank of 6 , and a higher rank of 8 among similar schools, indicating it outperformed most demographically similar schools. Although it did not meet AYP targets in 2008-2009, primarily due to the performance of subgroups (excluding whites and 
Asians) on math CSTs, IMS distinguished itself by being the only case-study school that met AYP criteria for percent of ELs proficient in English language arts.

\section{Results}

\section{Entry into EL Curricular Streams}

Schools had well-defined policies and criteria for curricular placement. EL status, CELDT ELP levels, and CST-ELA scores variously drove decisions regarding entry into EL or mainstream Curricular Streams. Once meeting EL curricular entry criteria, schools used students' performance levels for placement into specific EL Curricular Streams. For all schools, High Point, a language and literacy curriculum with strategies for ELs and struggling readers, was the primary or supplementary curriculum for ELD/ELA instruction. Three of the four schools used High Point's Developmental Placement Inventory (DPI) for specific placement within the curriculum. In all four schools, the majority of ELs arrived with scores on these assessments, so EL coordinators typically placed them, according to district guidelines adapted to meet the needs of their particular student and curricular contexts. For newcomers to the US, EL coordinators usually administered and scored the CELDT to determine initial placement.

\section{Curricular Streams in the Context of School Cultures}

Across the four cases, characteristics of Curricular Streams reflected adaptations to district guidelines as well as particular school cultures varying in leadership, distributed responsibility, and prioritization of EL achievement. All schools used a six-period schedule, which included physical education, a state requirement.

\section{Curricular Streams and School Culture at CMS}

Interviews revealed a school culture in flux after the recent hiring of two new vice principals. According to staff, with five different academic principals in as many years, leadership regarding EL matters had been traditionally delegated to the EL coordinator, and ELs tended to be the concern primarily of the cadre of teachers involved in the EL program. ELD/ELA teachers participated in common planning time and sharing of best practices at the school and district levels, yet administrators reported little schoolwide uptake of SDAIE and differentiated instruction intended to improve student learning. Staff did not report systematic use of performance data to inform instruction.

CMS had five Curricular Streams for EL students, and it used multiple criteria for placement (see Fig. 1): CELDT ELP levels, number of years enrolled in US schools, and CST-ELA performance. Its two ELD/ELA streams, in which $22 \%$ of its ELs enrolled, were for those who were at Beginning to Early Advanced levels of ELP, performed Basic or below on the CST-ELA, and were in EL status for less than 4 years. Students enrolled in a two-period ELD/ELA block, which provided 


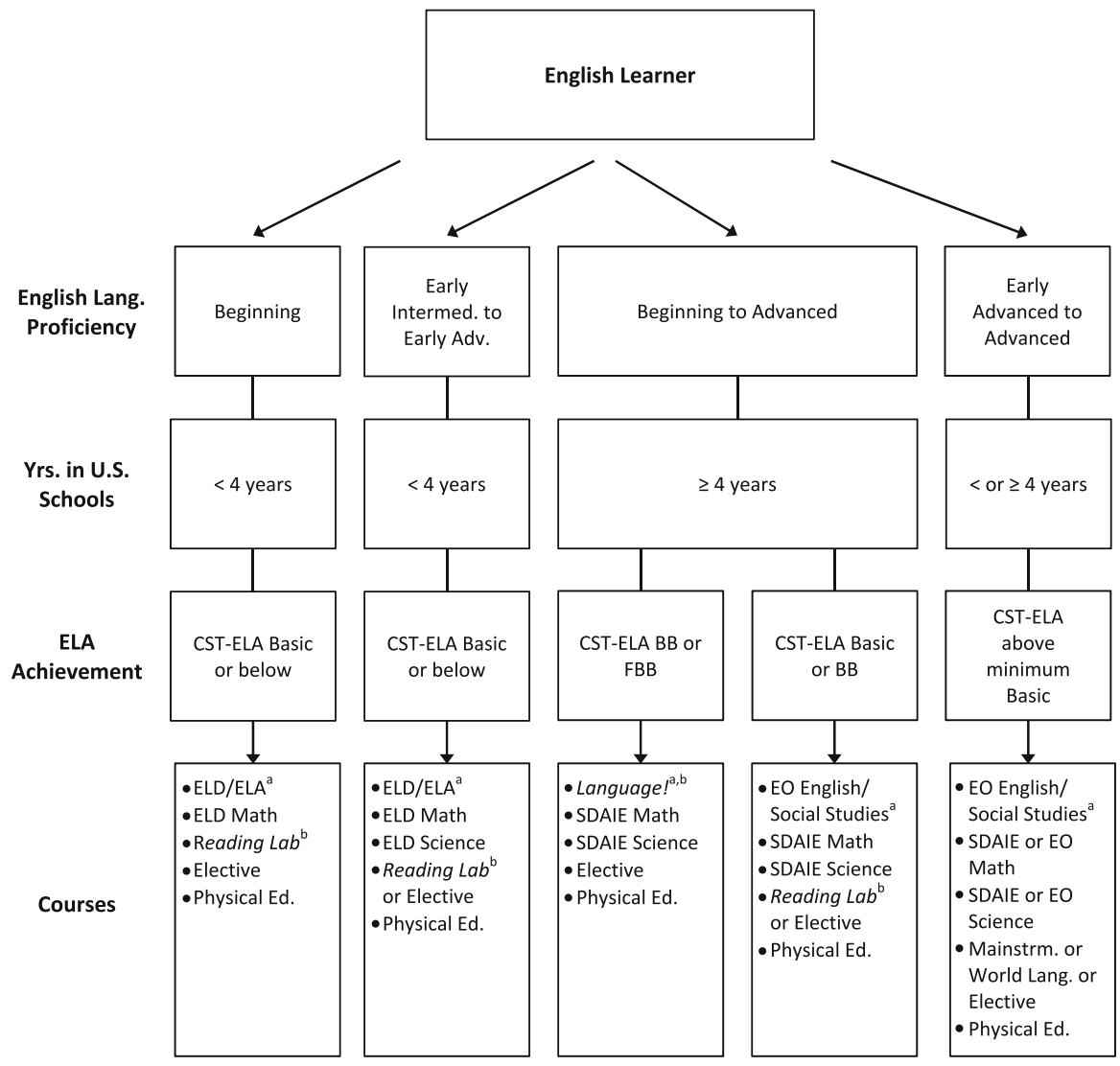

Fig. 1 Cove Middle School English learner Curricular Streams. English learners were placed in Curricular Streams based on English language proficiency levels as assessed by the California English Language Development Test, years enrolled in US schools, and performance on the California Standards Test-English Language Arts (CST-ELA). CST-ELA performance levels are Far Below Basic (FBB), approximately 3 years below grade level; Below Basic (BB) approximately 2 years below grade level; Basic, approximately 1 year below grade level; Proficient, grade level; and Advanced, above grade level. ELD denotes English language development; ELA denotes English language arts; EO denotes English only. SDAIE denotes specially designed academic instruction in English. Twenty-two percent of ELs enrolled in the two ELD/ELA streams; $78 \%$ enrolled in the other three streams. ${ }^{\text {a }}$ These courses were twoperiod blocks. ${ }^{\mathrm{b}}$ These courses were reading interventions

ELD instruction with the High Point curriculum at a decelerated pace and very limited access to core ELA. Rather than the publisher's recommended pace of 3 years ending at the sixth-grade level, CMS used a 3-year cycle ending with the fifth-grade level. Students who entered at beginning levels emerged from middle school having completed the fifth-grade curriculum. The ELD/ELA teachers lamented the shortcomings of the curriculum, including lack of alignment with state ELA grade-level standards, slow pacing, and insufficient opportunities for reading and comprehending longer, connected text and for writing. They explained that because High Point aligned with ELD standards only, student achievement of the 
ELA standards remained enormously challenging. In response they tried "squeezing" in core literature and standards periodically. Moreover, teachers emphasized that without prior core ELA teaching experience, ELD/ELA teachers would not know how to incorporate ELA core content. Thus, access to core ELA depended on teachers' familiarity, capacity, and willingness.

In these streams access to other core content was also very limited and students were isolated most of the day. ELs enrolled in a restricted set of multigrade (sixth through eighth grade) EL-only, ELD content courses. Beginning ELP students forwent science and both beginners and Early Intermediate to Early Advanced ELs forwent social sciences. Staff reported that ELD math and science courses used Access Math and Access Science, non-core curricula. According to the publisher, Access curricula are designed to complement core curricula in fifth through twelfth grades for special education and ESL students, covering the "big ideas in English, math, life, earth, and physical science" (Great Source 2009).

Additionally in these streams, based on a combination of teacher recommendation and CST-ELA performance at Basic or BB, students often enrolled in Reading $L a b$, an EL-only, site-based multigrade reading intervention. Offered at beginning, intermediate, and advanced levels, it was designed to support reclassification and to address the shortcomings of High Point. Without appropriate support and gradelevel curricula, the Lab's teacher reported trying a variety of approaches targeting reading, vocabulary, and comprehension specifically, but not writing, nor specific content standards such as simile or metaphor. Reading Lab thus functioned as an additive intervention, which eliminated students' elective, further narrowing students' access to the full curriculum and to non-EL students. Thus in the ELD streams, ELs had little access to the core and full curriculum, were often enrolled in an additional remediation intervention, forewent electives, and were isolated both academically and socially.

Placement in the three Curricular Streams for students who had been ELs for 4 years or more, depended on ELP and CST-ELA performance; $78 \%$ of CMS' ELs enrolled in these streams. Regardless of ELP level, students in all of these streams were ineligible for ELD instruction. Instead, for students at Beginning to Advanced levels of ELP whose CST-ELA performance was BB or FBB, Language!, a 2-year, two-period block reading intervention originally designed for special education students, replaced ELD and ELA. The first year covered second- and third-grade reading levels and the second covered fourth- and fifth-grade levels. Students in Language! were heavily, but not exclusively, EL. Students also enrolled in EL-only SDAIE core math and science, and an elective, but not social studies. Thus, these students did not have access to all core content area, and they remained mostly academically and socially isolated.

Students who were at Beginning to Advanced levels of ELP whose CST-ELA performance was Basic or BB, as well as the overflow of students needing Language!, usually enrolled in English only (EO) English/social studies core (due to the unavailability of SDAIE English), EL-only SDAIE core math and science and Reading Lab, which eliminated their elective. Somewhat less isolated, these students had access to all core content areas, but not to the full curriculum, and remained academically and socially isolated about half of the day. 
Students at Early Advanced and Advanced levels of ELP, whose CST-ELA performance was above the minimum Basic level, enrolled in EO core English/ social studies and either in EL-only, core SDAIE math and science or EO core math and science. Although these students had access to all traditional core content areas and were less isolated, they did not necessarily have access to all IB courses. CMS denied ELs enrollment in Mainstream or World Language (Spanish or Portuguese), an IB requirement, until they were ready to reclassify. A staff member explained that EL students needed literacy first: "When they had EL students, the foreign language teachers hated it, because they had students who were not literate in Spanish...they would say 'hui' instead of 'fui' and 'muncho' instead of 'mucho." As evidence of the policy's success, she pointed to the current $60 \%$ pass rate of ELs on the district's Spanish high school equivalency exam, attributing their performance to transferring literacy from English to Spanish.

In practice, until students had reached at least Early Advanced levels of ELP and were at above minimum levels of Basic on the CST-ELA, CMS' Curricular Streams emphasized developing English proficiency for reclassification rather than promoting grade-level content mastery. According to one staff, “...the focus is teaching English quickly to pass the California State High School Exit Exam. ... we are not so concerned about what the Louisiana Purchase is. We would rather have the student in a smaller class so he can be in ELD [courses] talking and moving ahead [with English]..." Some staff and the new administrators voiced concerns about the resulting slow movement through ELD/ELA, separate multigrade, ELD non-core content and intervention courses, restricted access to core curricula, insufficient challenge, and delayed entry into the full mainstream curriculum. According to staff, after completing the ELD and/or reading intervention curricula, at the end of eighth grade, students typically emerged below grade level (fourth and fifth grade). Propelled by these concerns, these administrators had begun departmental meetings centered on student performance on district benchmarks in language arts and math, and they were planning several changes for the following year to accelerate students' movement through the ELD curricular program and to provide more timely access to the core.

\section{Curricular Streams and School Culture at KMS}

KMS' school culture was shifting as staff confronted increasing numbers and mainstreaming of ELs, a newly implemented policy. Led by the principal and the EL teachers, a number of efforts were underway to prioritize and improve teaching and learning for ELs, including: principal observations focused on reducing teacher talk and increasing student talk; peer coaching and modeling; using data to target specific students and inform instruction; supporting National Board Certification; and onsite professional development on academic language development and thinking maps. During observations we did not observe the strategies the principal was promoting such as 10-min chunks of teacher presentation followed by 2 min of student processing in participation structures such as Think-Pair-Share. Teachers reported whole-school and departmental discussions on teaching and learning based on student performance on the CELDT, CST, and/or benchmarks. Many teachers 
reported school-wide targeting of "focus students" to whom they provided extra support.

The principal and EL teachers were propelled by a confident attitude and the awareness that the only way to increase KMS' API score was to improve the performance of ELs. According to one, "We can get $100 \%$ (of ELs to CST proficiency levels), if we get everyone on board." Simultaneously, outside this core group, uptake among teachers varied and these staff reported that the union's "hand off-no evaluation" approach at times hampered their efforts and bolstered resistant teachers.

KMS had three different Curricular Streams for EL students, although it was in the same district as CMS. It used the same placement criteria categories: CELDT ELP levels, CST-ELA performance, and number of years enrolled in US schools, but the performance levels differed (see Fig. 2). The ELD/ELA stream, in which $11 \%$ of ELs enrolled, was restricted to ELs who were at Beginning to Early Intermediate levels of ELP, performed Basic or BB on the CST-ELA, and were in EL status for less than 4 years. Students enrolled in a three-period, multigrade ELD/ ELA/social studies block that provided ELD with the High Point curriculum at a decelerated pace and very limited access to core ELA and social studies. Like CMS, KMS used High Point on a decelerated schedule, but it provided a 2-year rather than 3-year program, beginning with Introduction and ending with the fourth-grade level. Like staff at CMS, teachers expressed frustrations about the slow pacing and lack of alignment with core ELA standards, in addition to the lack of access to core social studies. Without a standards-based social studies curriculum, staff attempted to teach some key concepts using a high-interest, low-reading-level series. In addition, in response to the lack of in-depth reading opportunities in High Point, a computerbased reading intervention replaced social studies altogether during the second semester. In this stream students also enrolled in core math and science, an elective, and physical education. Thus, these students had access to these core content areas and were integrated with non-ELs about half of the day. Because science was one semester, students were able to take a one-semester visual and performing arts elective, typically at the beginning levels. To gain eligibility to a magnet visual and performing arts high school, however, students needed to complete advanced courses. This stream precluded this option and staff reported that these students often reverted back to neighborhood high schools in the urban center.

The second stream, a combination of remediation and core courses in which $42 \%$ of ELs enrolled, was for two kinds of students whose CST-ELA performance was BB or FBB: (a) those who were at Beginning to Early Intermediate levels of ELP and had been in EL status for 4 or more years, and were therefore no longer eligible for ELD instruction; and (b) those who were at Intermediate to Advanced ELP regardless of number of years in EL status. Reading and writing interventions replaced ELD, ELA, and for sixth graders, social studies as well. These students enrolled in a two-period Language! block, core social studies (as a cohort), core mainstream math, core science (one semester as a cohort), and an elective (one semester) or Writing Intervention (one semester), a site-based intervention intended to address the dearth of writing opportunities in Language!. In both interventions, the vast majority of students were ELs. Similarly, in response to the lack of in-depth 


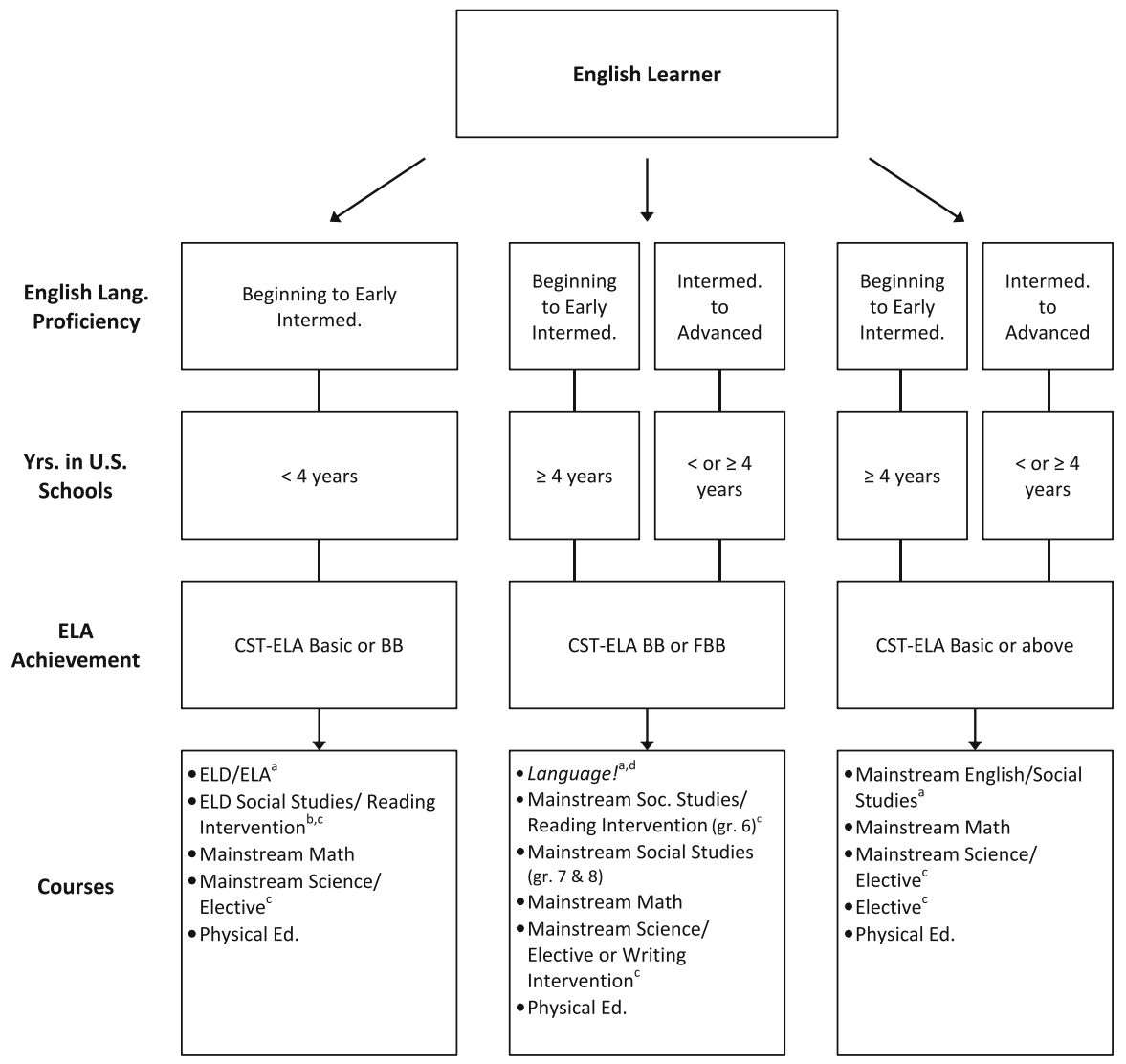

Fig. 2 Knoll Middle School English learner Curricular Streams. English learners were placed in Curricular Streams based on English language proficiency levels as assessed by the California English Language Development Test, years enrolled in US schools, and performance on the California Standards Test-English Language Arts (CST-ELA). CST-ELA performance levels are Far Below Basic (FBB), approximately 3 years below grade level; Below Basic (BB) approximately 2 years below grade level; Basic, approximately 1 year below grade level; Proficient, grade level; and Advanced, above grade level. ELD denotes English language development; ELA denotes English language arts. Eleven percent of ELs enrolled in the ELD/ELA stream; $42 \%$ enrolled in the second stream involving interventions and some mainstream courses; $47 \%$ enrolled in the mainstream stream. ${ }^{\text {a }}$ These courses were two-period blocks. ${ }^{\mathrm{b}}$ These courses were coupled with ELD/ELA to form a 3-period block. ${ }^{\mathrm{c}}$ These courses were one semester each. ${ }^{\mathrm{d}}$ Language! is a reading intervention

reading opportunities in Language!, the computer-based reading intervention replaced social studies in the second semester for sixth graders. Consequently, sixth graders could conceivably enroll in four periods of additive interventions: Language!, the computer reading intervention, and Writing Intervention. Thus, students in this stream had no ELD instruction, no access to core ELA, limited access to core social studies, and were isolated much of the day in additive interventions. As in the ELD/ELA stream, these students had little opportunity to pursue advanced visual and performing arts electives. 
In the third Curricular Stream, KMS mainstreamed students whose CST-ELA performance was Basic or higher and whose ELP was at Beginning to Advanced levels, regardless of number of years in EL status; $47 \%$ of ELs participated in this stream. These students did not receive ELD. They had access all core content areas, the full curriculum, and were integrated with non-EL peers.

For the following academic year, in addition to the existing interventions, KMS was planning to enroll $24 \%$ of its ELs in a computer-based math intervention for sixth and seventh graders who had not achieved proficiency in CST-Math for 3 years. A greater proportion of ELs met the criterion for this intervention, but many were enrolled in the two-period Language! block and district policy precluded students from enrolling in more than one two-period block. The principal was trying to obtain an exception that would allow ELs to enroll in the math intervention in lieu of regular math.

KMS' lacked wholesale consensus about how to improve EL performance. Staff reported tensions among the goals of providing access to the core by integrating students into the mainstream and isolating them for remediation and preparation for reclassification. Within the social studies department for example, the principal reported heated debate over teaching content versus remediating students' reading, although in the end comprise prevailed: The following year, the computer-based reading intervention would replace social studies for the ELD and remediation Curricular Streams, and students would receive some instruction in key core social studies topics. One teacher who was not a proponent of multiple-period interventions, nonetheless complained bitterly about the impossibility of meeting the needs of diverse students within a single classroom, “...the truth is ELs could use a whole period of vocabulary preparation for stories and GATE students need 2 min. How do you implement [instruction] to be fair to all students?" She believed ability grouping by classroom was preferable. Yet, on balance, the teachers interviewed favored integration of students into the mainstream. They credited mainstreaming with EL improvements on the CSTs, touted the value of diverse abilities in the classroom, and asserted that ELs would not learn English in separate classes. However, access to core curricula and integration into the mainstream remained compromised for more than half of KMS' students due to its reliance on additive interventions.

\section{Curricular Streams and School Culture at DMS}

At DMS ELs were a small minority and did not appear to be a focal point. The work of directly addressing their needs appeared to be left to the EL coordinator and a small cadre of teachers. According to the principal, "You hire good people." DMS administrators indicated that in serving a large GATE population (60\%), they raised the bar, used good teaching practices for all, and in so doing served EL students. "Teachers are geared more to a high-level thinking process... The baseline is high, which includes ELs. If it is good for one, it is good for all ...it's scaled to the clientele...The ELs need more vocabulary, more concepts." One administrator asserted that teachers used SDAIE strategies across the board because "... they are good for all students," yet we observed only one teacher using one of the SDAIE 


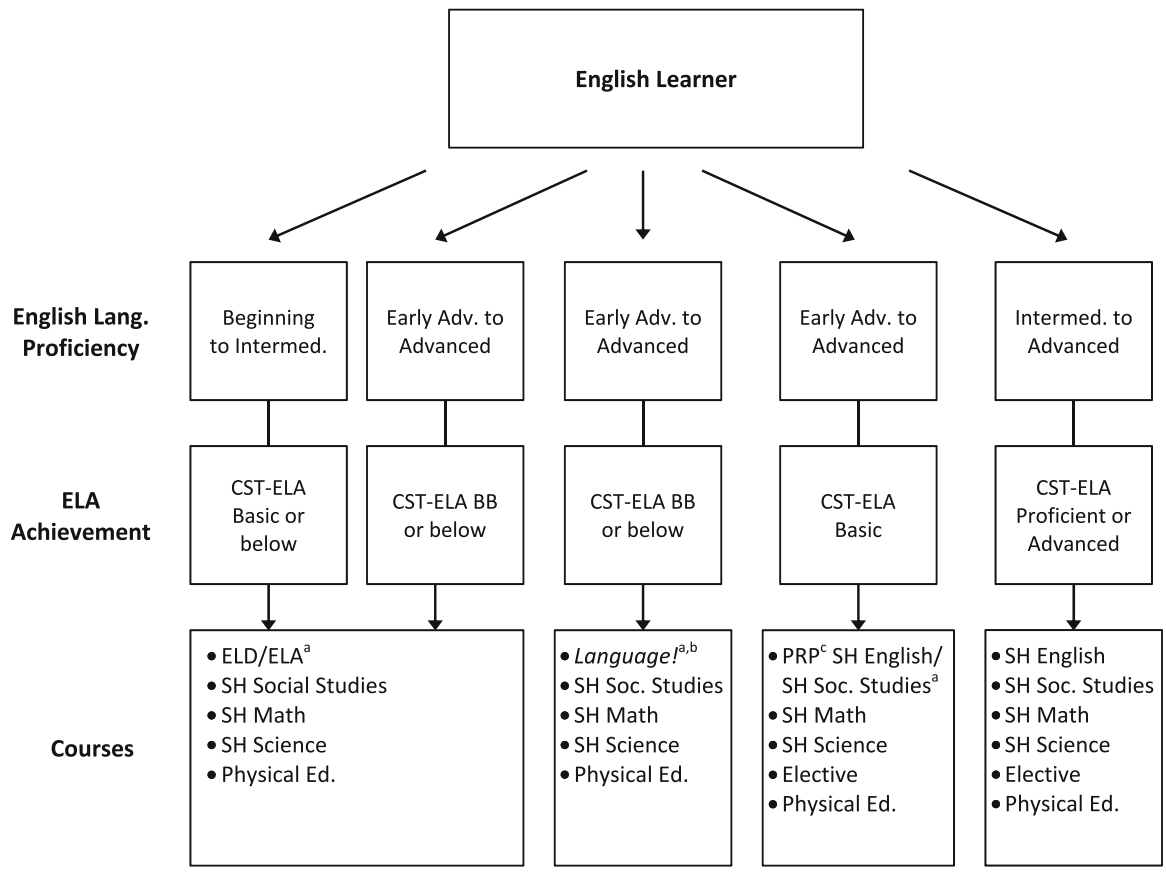

Fig. 3 Dell Middle School English learner Curricular Streams. English learners were placed in Curricular Streams based on English language proficiency levels as assessed by the California English Language Development Test and performance on the California Standards Test-English Language Arts (CST-ELA). CST-ELA performance levels are Far Below Basic (FBB), approximately 3 years below grade level; Below Basic (BB) approximately 2 years below grade level; Basic, approximately 1 year below grade level; Proficient, grade level; and Advanced, above grade level. ELD denotes English language development; ELA denotes English language arts; SH denotes sheltered instruction. Twentynine percent of ELs enrolled in the ELD/ELA stream; $5 \%$ enrolled in the second stream involving reading intervention and sheltered courses; $45 \%$ enrolled in the PRP/sheltered stream; $21 \%$ enrolled in the sheltered stream. ${ }^{\text {a }}$ These courses were two-period blocks. ${ }^{\mathrm{b}}$ Language! is a reading intervention. ${ }^{c}$ Preparing for Reclassification Program

strategies encouraged by the district. Although administrators mentioned a few activities emphasizing performance monitoring and instruction such as benchmark reviews and professional development on thinking maps, they did not target ELs per se. Moreover, they reported, "Uptake depends entirely on the teacher." No teachers reported participating in these activities; one reported a boycott of benchmark reviews. Overwhelmingly teachers were only vaguely aware of ELs' performances on these assessments. Among the small cadre, one staff explained, "Because their [EL] numbers are small, it is easier to focus on the greater majority and they are [the] GATE population."

DMS provided four Curricular Streams for ELs and used primarily two criteria for placement: CELDT ELP level and CST-ELA performance (see Fig. 3). It did not restrict ELD/ELA instruction based on number of years in EL status; rather it used a combination of ELP and achievement criteria to place students in ELD. DMS' ELD/ ELA stream, in which $29 \%$ of its ELs enrolled, was for ELs who were at Beginning 
to Intermediate levels of ELP and performed at Basic or below on the CST-ELA. Students at Early Advanced and Advanced levels of ELP who scored BB or below also enrolled in this stream. Students enrolled in a 2-period ELD/ELA block, which provided ELD and access to core ELA for advanced ELD students (but not for beginning to intermediate ELD). DMS used the full 3-year High Point curriculum at the recommended pacing, ending with the sixth-grade level. Within the most advanced ELD/ELA course, the teacher reported dividing the curriculum into two units of High Point and three units of grade-level ELA literary response and analysis, which we observed. These students forewent their elective and enrolled in multi-rostered, sheltered core math, social studies, and science, typically made up of ELs, low-performing EOs, and special education students. Thus in the ELD stream, ELs in advanced ELD had some access to core ELA, and all had access to core content areas and were integrated with low-performing non-EL peers, but isolated from other non-ELs.

The Language!/sheltered stream was for $5 \%$ of ELs who were at Early Advanced to Advanced levels of ELP, performed at BB or lower on the CST-ELA, and had Individual Education Plans after faltering in a sheltered ELA course for a year. Language! replaced ELD and core ELA, and students typically enrolled in multi-rostered, sheltered core content courses.

The Preparing for Reclassification/Sheltered stream (PRP), in which $45 \%$ of ELs enrolled, was for those at Early Advanced and Advanced levels of ELP who scored Basic on the CST-ELA. These students no longer received ELD instruction. They enrolled in sheltered PRP core English and social studies, a two-period, multirostered block with the same teacher, and in multi-rostered, sheltered core content courses. Based on teacher recommendation, seventh and eighth graders in this stream could enroll in honors classes in the SAS, but the EL coordinator reported that participation in these classes was probably "none."

The sheltered stream was for students at Intermediate to Advanced levels of ELP who scored Proficient or Advanced on the CST-ELA. They enrolled in sheltered core English, and typically, in multi-rostered, sheltered social studies, math, science, and an elective; they did not receive ELD instruction. Excluding English, these students could enroll in mainstream content courses based on teacher recommendation, though it was infrequent, according to staff. Twenty-one percent of ELs enrolled in this stream.

Thus, DMS provided ELD instruction through intermediate levels of ELP (and through Advanced for ELs performing 2 or more years below grade level), more access to the core curriculum, and integration with some non-EL peers. Staff also reported more focus on core content mastery than on ELP and reclassification. However, staff complained that DMS purchased access to the core and integration via multi-rostered sheltered courses with low-performing non-ELs, which precluded ELs' integration with higher performing students and resulted in a lack of good language and study-habit models. One staff member reported, "The students with good models have moved quickly; those without [good models] don't move forward...they get stuck." Reflecting on the separation of students into ELD, PRP, and sheltered streams within the neighborhood and magnet schools and separation from the honors school, another staff member said, "What are the other kids [those 
not in honors or the magnet programs] supposed to feel like-it segregates them and makes them feel bad." Staff also recounted resistance to teaching the PRP and sheltered courses. "Teachers don't want to take sheltered classes." Those who elected to do so appeared particularly committed, however. One said, "This is my favorite class and the most work." Another said, "They want to learn. I wanted to teach them, because it was chaos with a former teacher." Concern about these students clearly drove these teachers. Nonetheless, DMS curricular placement decisions appear to have isolated and stigmatized both ELs and their teachers.

\section{Curricular Streams and School Context at IMS}

At IMS the principal was leading efforts to improve teaching and learning for all students, while targeting EL achievement. With a core cadre of teachers, she established a number of schoolwide practices aimed at engaging all of the staff in achieving specific instructional, learning, and performance goals. The first was dedicating time and resources to review standards and student performance to inform practice. To adjust their practices using data, teachers reported both individual- and department-level review of the following: CST scores, CELDT levels, quarterly benchmark performance, and other individual student data available to them electronically within their classrooms. The second was implementing innovative grouping, curricular, and scheduling strategies. For example, the math department had targeted students scoring Basic and BB on the CST-Math, separated them by gender, and placed them in two-period prealgebra blocks with some of its best teachers. The third practice was providing teachers authority to adapt pacing calendars and curricula. Math teachers slowed the district pacing calendar, emphasizing depth rather than breath and focusing on essentials that would prepare students for both CST-Math and algebra the following year. Among the principal's instructional goals was increasing student active engagement (e.g., white boards, increased wait time), student talk (Think-PairShare), and academic language use. We observed these practices in several classrooms. Another of the principal's goals was personalizing the school-teachers knowing and connecting with students more closely. During observations, several teachers exhibited patience and warm relations with students, while maintaining academics at the center of their teaching. The principal reported that although uptake among teachers was yet not wholesale, she was recruiting more and more good teachers. She attributed IMS' large, consecutive 2-year gains in API to all of these practices.

IMS provided three Curricular Streams for ELs and used primarily ELP level for placement (see Fig. 4). It provided ELD instruction through intermediate levels of ELP and did not restrict it based on number of years in EL status. It built its master schedule around math first and ELP second, placing all student in math based on CST performance. IMS used no remedial interventions.

IMS had two ELD streams, in which $54 \%$ of ELs enrolled. In its ELD stream for Beginning to Early Intermediate levels of ELP, ELs enrolled in a three-period ELD/ ELA block, which used the High Point curriculum at an accelerated pace and stressed grade-level ELA standards, according to the teacher. These ELs also 


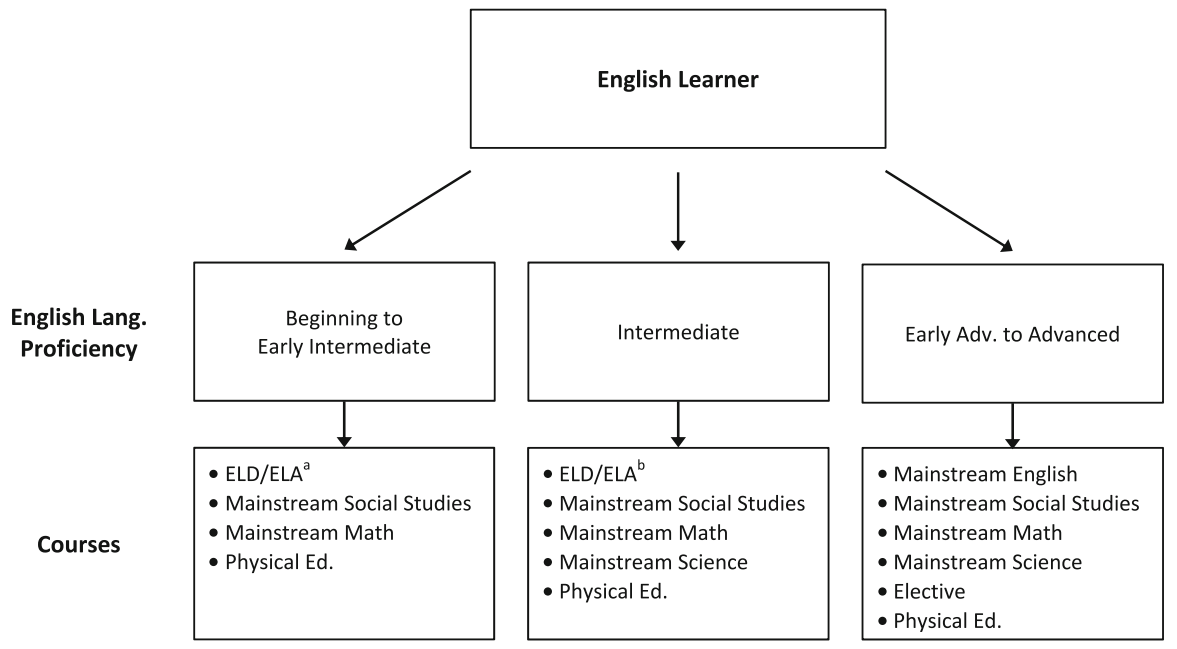

Fig. 4 Interior Middle School English learner Curricular Streams. English learners were placed in Curricular Streams based on English language proficiency levels as assessed by the California English Language Development Test (CELDT). ELD denotes English language development; ELA denotes English language arts. Fifty-four percent of ELs enrolled in the two ELD/ELA streams; $46 \%$ enrolled in the mainstream Curricular Stream. ${ }^{\text {a }}$ These courses were a three-period block. ${ }^{\mathrm{b}}$ These courses were a twoperiod block

enrolled in mainstream core social studies, as a cohort, and core math. These students forewent science and an elective, thus they had some, but not full access to the core, and were isolated half the day.

In its ELD stream for Intermediate ELP, students enrolled in a two-period ELD/ ELA block, which used Holt Plus Literature, a seventh-grade core ELA curriculum adapted for struggling readers. To supplement the ELA core with ELD instruction the teacher used High Point at an accelerated 2-year rather than 3-year pace. She explained, "... there is no way I would teach that book even 1 year...High Point is at a lower level and not connected to the [ELA] content standards, so it doesn't prepare them for the CSTs. I use the Holt pacing to prepare them for the benchmark tests." Researchers observed this teacher using the seventh-grade Holt curriculum and teaching students academic content vocabulary (character analysis, plot, foreshadowing, theme) in preparation for writing a response to literature. She asserted that after a year in her class, most students reached Early Advanced or Advanced levels on the CELDT and moved on to mainstream ELA. These students forewent their elective and enrolled in mainstream core social studies, math, and science, which afforded substantial access to the core and integration with non-ELs.

In the third Curricular Stream, IMS mainstreamed ELs at Early Advanced to Advanced levels of ELP; they comprised $46 \%$ of ELs. These students did not receive ELD instruction. They had access to all core content areas, the full curriculum, and were integrated with non-ELs.

At IMS its staff consistently reported, and observations revealed, a focus on grade-level content, rather than ELP or reclassification. They also touted their two 
pathways to its GATE program: The first relied primarily on test scores and the second relied more on teacher recommendations. Concerned about the how well IMS was serving EL students and trying to focus teacher efforts further, the principal planned to begin the following year by asking teachers to reflect and answer the questions, "You can tell who my EL students are in my class because...?" and, "What are you doing for the EL students every time [you] meet?"

\section{Exit from EL Curricular Streams into the Mainstream}

The four schools had distinct criteria for exiting ELs from EL Curricular Streams. KMS exited ELs from EL Curricular Streams and placed them in the mainstream when they: (a) scored Basic or above on the CST-ELA and (b) were at Intermediate to Advanced levels of ELP or (c) scored Basic or above on the CST-ELA and had been in US schools for 4 or more years, regardless of ELP level. IMS placed ELs at Early Advanced and Advanced levels of ELP in the mainstream. At CMS and DMS complete exit out of EL Curricular Streams and into the mainstream and other streams required reclassification to fluent English proficient. Thus, reclassification functioned as a gateway to full access and integration at CMS and DMS.

Across the schools, variation in district reclassification procedures and criteria resulted in local definitions of EL status (see Table 5). All districts used the CELDT criterion for ELP, the CST-ELA, additional academic performances, teacher recommendations, and parent consultation/notification. But, IMS used the CSTMath as well, and across the schools, the performance threshold on the CSTs varied from Basic to Proficient. Additional district-specific performance criteria also varied

Table 5 Reclassification criteria in four case study middle schools

\begin{tabular}{|c|c|c|c|c|c|}
\hline Criteria & Cove MS & Knoll MS & Dell MS & $\begin{array}{l}\text { Interior } \mathrm{MS}^{\mathrm{a}} \\
\text { option A }\end{array}$ & $\begin{array}{l}\text { Interior MS } \\
\text { option B }\end{array}$ \\
\hline $\begin{array}{l}\text { CELDT criterion for } \\
\text { English Prof. }\end{array}$ & $\sqrt{ }$ & $\sqrt{ }$ & $\sqrt{ }$ & $\sqrt{ }$ & $\sqrt{ }$ \\
\hline CST-ELA $^{\mathrm{b}}$ & 317 & 317 & 300 & 350 & 324 \\
\hline CST-math ${ }^{\mathrm{b}}$ & - & - & - & 350 & 324 \\
\hline Teacher rec. & $\sqrt{ }$ & $\sqrt{ }$ & - & $\sqrt{ }$ & $\sqrt{ }$ \\
\hline Parent consult. & $\sqrt{ }$ & $\sqrt{ }$ & $\sqrt{ }$ & $\sqrt{ }$ & $\sqrt{ }$ \\
\hline Writing sample & Grade level & Grade Level & - & - & - \\
\hline Adv. ELD or English grade & - & - & $\mathrm{C}$ or higher & - & - \\
\hline Holt writing assessments & - & - & - & - & $75 \%$ \\
\hline Holt reading assessments & - & - & - & - & $80 \%$ \\
\hline Pre-algebra assessments & - & - & - & - & $70 \%$ \\
\hline Algebra assessments & - & - & - & - & $70 \%$ \\
\hline
\end{tabular}

$\sqrt{ }$ indicates that the criterion was used. Hyphens indicate that that the criterion was not used

${ }^{a}$ Interior City Middle School alone had two options for reclassifying using two different sets of criteria

${ }^{\mathrm{b}}$ Range of scores $=150-600$; Basic (approximately 1 year below grade level) score range $=300-349$; Proficient (at grade level) score range $=350-400$ 
widely from grade-level performance on district-wide writing assessments to specific grade minimums in English language arts, mathematics, and ELD/ELA classes. Taken together, the range of the stringency was striking. The least stringent criteria at DMS involved a CST-ELA score at Basic or higher and an English or advanced ELD grade of $\mathrm{C}$ or better. The most stringent at IMS involved CST-ELA and CST-Math scores at Proficient or higher and a teacher recommendation, or alternatively, scores in the mid-Basic to just below Proficient range, in combination with multiple curriculum-embedded assessment performance criteria and a teacher recommendation (see Table 5).

Variation in the criteria for reclassification and in school demographics makes direct comparisons of reclassification rates inexact. As might be expected DMS, with the least rigorous criteria, reclassified $31.1 \%$ of its ELs. However, ICMS, with the most rigorous criteria and a high percentage of free and reduced lunch eligibility, reclassified $18.3 \%$ of its EL students, close to double the state average of $10.8 \%$. CMS and KMS, in the same district with identical criteria, produced very different reclassification rates of 12.2 and $27.6 \%$, respectively (see Table 4), though they were also very different demographically.

\section{Comparative Analysis and Discussion}

\section{Conclusions}

Several broad conclusions can be drawn from the findings. First, Curricular Streams afford distinct opportunities for ELD instruction, access to core content and the full curriculum, and integration with non-EL peers. Second, due to variation in reclassification criteria, EL status is locally defined, yet reclassification can function as a gateway to the mainstream and more advanced Curricular Streams thus affecting EL access and integration. Third, curricular and policy limitations make it challenging for schools and teachers to address students' ELD and core content needs and persistent underachievement, often resulting in the use of additive interventions. Fourth, in the context of local control policies and curricular constraints, Curricular Streams intended to meet EL needs vary widely in the relative emphasis they place on ELP versus core academic content, remediation versus acceleration, and isolation versus integration. Finally, school cultures that focus on improving instruction and achievement for all, while targeting ELs and increasing distributed responsibility among staff, appear to benefit both students and teachers. The few commonalties across the four schools were similar processes for entry into EL Curricular Streams, the use of CELDT ELP levels for placement, and provision of ELD instruction to ELs at Beginning through Early Intermediate levels. Noteworthy is that despite research-based guidelines to provide ELD through early advanced ELP, only one school did so and only for ELs with very low CST-ELA achievement. Beyond these features, variation reigned, even between the two schools in the same district. 
Curricular Streams: An Instantiation of Differing Philosophies Regarding English Language Proficiency, Reclassification, Access to Core Content, and Integration

Across the cases, the Curricular Streams appeared to reflect differing philosophies that produced distinct programmatic emphases along a continuum. At one end of the continuum was an emphasis on English language proficiency and reclassification, coupled with remediation and decelerated pacing, often with non-core curricula, and isolation of ELs. On the other end of the continuum was an emphasis on access to the core curriculum and standards coupled with acceleration and standard pacing with grade-level curricula and more rapid integration of ELs.

Six related factors drove students' access to ELD instruction, access to the core and full curriculum, and relative isolation or integration. One was the CELDT ELP levels at which schools provided ELD. Another factor was whether schools limited ELD based on number of years in US schools, regardless of English proficiency level. A third factor was whether schools used High Point as the main ELD/ELA curriculum, or as a supplement to core curriculum; whether schools used the entire 3-year High Point curriculum; and whether the pacing was decelerated, standard, or accelerated. A fourth factor was the extent to which schools relied on interventions to replace ELD and ELA for the lowest performing ELs. A fifth factor was the extent to which schools provided core content via ELD, sheltered, or mainstream courses. A sixth factor was whether reclassification functioned as the gateway to the mainstream and more advanced streams.

Curricular Streams Emphasizing English Language Proficiency, Remediation, Deceleration, non-Core Curricula, and Isolation

CMS was at one end of the continuum. For students with less than 4 years in EL status, Curricular Streams were characterized by slow movement through ELD, limited access to core ELA, no access to other core content, remediation, and isolation. For low-performing students with 4 or more years in EL status, Curricular Streams were characterized by replacement of ELD and ELA instruction with additive remedial interventions, limited access to the core and full curriculum, and relative isolation from non-EL peers. Higher performing ELs had more access to the core and were less isolated, but even they did not have access to all core courses and the entire curriculum. Achieving English language proficiency appeared to be seen as an end in itself and a prerequisite to profiting from grade-level content instruction. Moreover, ignoring the robust finding that literacy in the first language is the best predictor of success in the second language (Goldenberg 2011, 2013), Spanish was considered a deficit rather than a fund of knowledge (Moll et al. 1992). Reclassification was the gateway for exiting EL Curricular Streams, entering the mainstream, and gaining full access to the core and integration with non-ELs.

According to staff, students entering at early levels of ELP typically remained isolated in the ELD track during their entire 3-year stay. Many students emerged from the ELD/ELA and remedial programs below grade level and did not reclassify. These reports are consistent with those of other researchers who have found that 
students in low or remedial tracks tend to fall further behind (Oakes 1990; Oakes and Lipton 1999). And, it is particularly concerning in light of the findings by Flores et al. (2009) that, after taking other factors into account, reclassification rates plummeted after eighth grade, while reclassification as late as eighth grade predicted higher Stanford Achievement Test-9 scores in reading and math in eighth grade and increased the odds of taking an AP course, high school completion, and passing the high school exit exam.

This curricular approach, which occurred within a school context characterized by a lack of administrator leadership and by responsibility concentrated among the EL teachers, appeared to negatively affect teachers' sense of efficacy and views of their students' potential to succeed. Teachers in the ELD/ELA program shared their frustrations about the lack of access to core ELA as well as with students' and their own isolation. They relied on own their capacities to provide access to the core despite the rigid curricular structure and lack of support. Some teachers' comments reflected hopelessness, referring to some ELs as "lifers" who were doomed to remain ELs for the duration. One teacher decided to leave the ELD curricular stream altogether the following year.

Curricular Streams Emphasizing Access to Core Content, Acceleration, and Integration

At the other end of the continuum was IMS with Curricular Streams that emphasized access to core grade-level curricula and standards while concurrently developing English proficiency. IMS' Curricular Streams were characterized by brisk movement through ELD/ELA with simultaneous access to ELA grade-level standards and more rapid enrollment in grade-level content courses and integration into the mainstream. IMS eschewed remedial interventions. Its ELD/ELA courses used core-ELA curriculum and supplemented it with the High Point curriculum, delivered at an accelerated pace. ELD instruction, provided through Intermediate levels of ELP, regardless of CST-ELA performance or number of years in US schools, appeared to be seen as a means to access grade-level content, rather than an end in itself. Reclassification did not function as the gateway into the mainstream.

This curricular approach, which occurred within a school context characterized by active principal leadership focused on improving teaching and learning for all, while targeting EL achievement and engaging all teachers, appeared to benefit both teachers and ELs. Teachers considered by the principal as some of IMS' best taught in the EL Curricular Streams and they espoused confidence in themselves and their students. One teacher emphasized the importance of teacher pedagogical and content knowledge and knowledge of students, "You have to know your clientele. You have to break down [math] learning into steps. What are your prerequisites? What do students need to know in order to learn the concept or the problem you want them to learn?" These comments revealed that teachers viewed themselves as teachers of all students and their ELs as agentic, consonant with the teacher in Yoon's (2008) study who positioned ELs as strong. 
Curricular Streams Undermined by Over Reliance on Remediation

Between the two ends of the continuum were KMS and DMS. KMS' Curricular Streams revealed a struggle to find a balance between providing access to the core and remediation. Its EL Curricular Streams were characterized by relatively quick exit out of ELD/ELA and integration into the mainstream, but only for students scoring Basic or above on the CST-ELA. Simultaneously, KMS relied heavily on remediation, which limited access to the core and isolated a little more than half of its ELs. KMS' aim to make ELs everyone's students, in part by quickly integrating ELs into the mainstream, succeeded for nearly half of its ELs, but was undermined for the rest by its use of additive interventions to address the enduring dilemma of significant numbers of ELs who had completed ELD/ELA or were no longer eligible and were persistently low-performing in English language arts. Reclassification was not the gateway for exit from EL Curricular Streams and full entry into the mainstream.

The unresolved tensions in this curricular approach occurred within a school context characterized by principal leadership aimed at improving instruction, in part by implementing more remediation and engaging teachers in focusing on ELs. This tension was mirrored in its teachers, with several reporting responsibility for and confidence in ELs' capacities to achieve, and some reporting that students needed to take more responsibility. The principal commented on disputes among teachers about remediation versus learning academic content.

Curricular Streams Undermined by Over Reliance on Multi-Rostering and Isolation of ELs and Their Teachers

DMS' Curricular Streams emphasized developing ELP while providing access to the core. Its Curricular Streams were characterized by standard-paced progression through ELD/ELA for students through Intermediate levels of ELP, coupled with access to the core in the other content areas as well as access to the core for students at Early Advanced and Advanced levels of ELP. Very few of its ELs participated in remedial interventions. However, its reliance on multi-rostered sheltered content courses to deliver access and to integrate ELs had unintended consequences, including lack of good language and study-habit models, limited opportunities to participate in the full curriculum, including the honors school within the school, and isolation and stigmatization for both ELs and teachers. Reclassification was the gateway into the mainstream and advanced streams and integration with averageand higher-performing non-EL peers. Even for students who were at Intermediate to Advanced levels of ELP and Proficient or Advanced on the CST-ELA, participation in the mainstream required teacher recommendations, which staff reported were rare.

This curricular approach occurred within a school context characterized by administrative leadership who contended that by serving a majority GATE population, the school raised the bar for all, including ELs. Administrators relied on the English language coordinator and a small cadre of teachers to address the 
needs of its small EL minority. These staff expressed both commitment to ELs and frustration with their own and students' isolation and stigmatization.

\section{Co-Occurrences of Curricular Streams' Emphases and Markers of School Performance}

Interestingly, the two cases representing the two ends of the continuum also represented the two ends of the continuum on markers of overall school performance (see Table 3). IMS was a rising school that had made major gains in the API, nearing the state target of 800 and ranking 8 among similar schools. CMS was at the other end, ranking 2 among similar schools, although it made gains in 2008-2009 after losing ground in years past. Notably, the school culture of IMS most closely resembled those previously identified in effective schools for ELs (Parrish et al. 2006; Williams et al. 2010). It is important to acknowledge that demographic differences may have played a role and that the data are instances of co-occurrence.

Ironically, CMS had the lowest rate of reclassification, despite its focus on ELP and reclassification, though perhaps not unexpectedly. Reclassification required meeting a mid-Basic score on the CST-ELA, which assesses precisely the core content CMS de-emphasized. The other three schools all had high rates of reclassification to fluent English proficient ranging from nearly 1.75 times higher than the state rate for IMS, with the most stringent criteria, to 2.5 times higher for KMS, which was in the same district with the same criteria as CMS, to nearly 3 times higher for DMS, with the least stringent criteria. It is important to note that demographic differences and self-selection may have played a role in the high rates of reclassification at DMS and KMS. Nonetheless, the three schools' stronger emphasis on providing access to the core may have also played a role in the higher rates of reclassification. Again, these data represent co-occurrences, not causal relations.

Implications for Research, Policy, and Practice

The results point to several implications and hypotheses. First, the concept of Curricular Streams is a powerful tool for describing and analyzing EL curricular placement and affordances regarding ELD instruction, access, and integration. An overarching implication of the results is that despite the desirable intention of EL designation to confer appropriate support, remaining EL in secondary school may delay entry into the mainstream, access to core content, and integration with non-EL peers. Relatedly, over the long term, ELs and their teachers may become isolated and stigmatized in EL-specific Curricular Streams. Local definitions of EL status and the use of reclassification to fluent English proficient as a gateway to the mainstream can exacerbate barriers for EL access and integration. Moreover, policies that limit ELD instruction based on years in EL status may not only deny students needed instruction, but may also prevent staff from assessing and finetuning responses to individual student needs. One hypothesis is that Curricular Streams that instantiate the view of ELP as a vehicle for developing academic 
content mastery and accelerating student progress, while providing access to gradelevel curriculum and integration into the mainstream, lead to higher student achievement and rates of reclassification. A related hypothesis is that school cultures characterized by principal leadership focused on improving instruction and achievement for all, while targeting ELs, and increasing distributed responsibility, will facilitate success for such a curricular approach. Conversely, Curricular Streams that focus on developing ELP, delay access to the core, rely on remediation, and isolate students are likely to lead to lower student achievement and rates of reclassification. Systematic, large-scale, multimethod quantitative and qualitative investigation of Curricular Streams, reclassification criteria and processes, coursetaking patterns, and achievement outcomes at multiple school levels in a variety of district and state policy contexts is important for elucidating these complex relations and informing policy and practice (see Estrada and Wang 2013).

Another important implication is that to meet EL needs, school staff bootstrap in the face of curricular inadequacies, insufficient support, and policy limitations on curricular choices such as limits on ELD instruction based on number of years in EL status. Some staff proliferate or adopt additive site- or computer-based interventions to address shortcomings. Others replace ELD and ELA instruction altogether with reading interventions intended for elementary-level special education students. Yet others develop ELD non-core content classes. Moreover, curricular limitations may in part explain why secondary ELs typically do not receive ELD instruction through early advanced ELP. Completion of the ELD curriculum may coincide with ELs' progression to intermediate and early advanced levels. In the absence of more curricular options, what to offer next may be unclear. Development of appropriate curriculum for ELD and content instruction for ELs at the secondary level and teacher support should be high priorities for both researchers and educators, especially as students and teachers grapple with adoption of the Common Core and Next Generation Science Standards (see Lee et al. 2013).

Finally, the finding that within broad state guidelines EL status is defined by local context raises questions of fairness, equity, and efficacy. For mainstream students, would stakeholders accept locally defined cut points for performance categories such as Proficient on content standards tests? Is local control of EL status and reclassification criteria and processes defensible when the potential consequences are so high for reclassification, access to core content, and integration with nonEL peers? Long overdue is a theoretically and empirically driven, evidence-based common standard definition of EL status and reclassification. In a significant step in this direction, the US Department of Education requires that states participating in the federally funded Common Core and EL assessment consortia develop a common definition of English learner. Fortunately a group of researchers, policy makers, and other stakeholders are collaborating on creating a cross-consortia common EL definition (see Linquanti and Cook 2013).

Like all studies, this one has limitations. Case study methods provide opportunities for description, hypothesis generation, and grounded theory building, not for generalization. Site visits occurred late in the year, when the teaching and curricular materials in use may have been different than earlier in the year. We could not gain access to all pertinent classes. However, restrictions on some classes 
occurred across the board in all schools, and the reasons were similar: lack of cooperation or quality teaching. I cannot say whether these classes varied systematically across sites. Another limitation is the lack of systematic data on interviewees' educational backgrounds and teaching experiences, which could help inform their responses. However, with the exception of two new vice principals, the vast majority of staff appeared to be seasoned veterans. Despite these limitations, the results are compelling.

These cases provide a more nuanced view of EL curricular experiences than previous research. I developed the concept of Curricular Streams and attendant graphics to represent and analyze the inordinate complexity and wide variation in EL programs, as well as the sense that upon entering a particular stream students were swept into that current and remained until they met school-specific exit criteria. The resulting implications and hypotheses are ripe for exploration. Taken together, these four disparate EL curricular programs represent serious effort, and one case provides a hopeful direction. Yet the lack of consistency and coherence suggests that schools are groping for solutions and it raises questions about the efficacy of EL state policy that relies on local control for interpretation. The stakes are high because limited academic preparation will limit ELs' long-term options to participate and contribute fully in our society.

Acknowledgments The William and Flora Hewlett Foundation provided funding for this study, which was part of a larger project on the education of English learners in California's middle schools, conducted by the Teacher Professional Development Program at WestEd. The contents, findings, and conclusions are the author's and do not necessarily represent the positions or policies of the Hewlett Foundation or of WestEd. I thank the participating teachers and principals for their thoughtful and candid responses. I also thank Claude Goldenberg and Patrick M. Shields for careful and critical reading of an earlier draft of this article.

Open Access This article is distributed under the terms of the Creative Commons Attribution License which permits any use, distribution, and reproduction in any medium, provided the original author(s) and the source are credited. Funding for Open Access was provided by the author and the University of California Santa Cruz Open Access Fund.

\section{References}

Abedi, J. (2008). Classification system for English language learners: Issues and recommendations. National Council on Measurement in Education, Fall, pp. 17-31.

Abedi, J., \& Dietel, R. (2004). Challenges in the No Child Left Behind Act for English language learners (Policy Brief 7). Los Angeles: University of California: National Center for Research on Evaluation, Standards, and Student Testing.

Aguila, V. (2010). Schooling English learners: Contexts and challenges. In Improving education for English learners: Research-based approaches (pp. 1-18). Sacramento: California Department of Education.

Batalova, J., Fix, M., \& Murray, J. (2007). Measures of change: The demography and literacy of adolescent English learners - a report to Carnegie Corporation of New York. Washington, DC: Migration Policy Institute.

Batalova, J., \& McHugh, M. (2010a). Number and growth of students in US schools in need of English instruction. Washington, DC: Migration Policy Institute. 
Batalova, J., \& McHugh, M. (2010b). Top languages spoken by English language learners nationally and by state. Washington, DC: Migration Policy Institute.

Bryk, A. S. (2010). Organizing schools for improvement. Phi Delta Kappan, 91(7), 23-30.

Bryk, A. S., Sebring, P. B., Allensworth, E., Luppescu, S., \& Easton, J. Q. (2010). Organizing schools for improvement: Lessons from Chicago. Chicago: University of Chicago Press.

California Department of Education. (2006). Frequently asked questions (FAQs) for ELs in California. Retrieved from http://www.cde.ca.gov/sp/el/er/.

California Department of Education. (2008). California English language Development Test (CELDT): Reporting and using individual 2008-09 results. Retrieved from http://www.callutheran.edu/schools/ education/accreditation/program_documents/multiple_single_standards/documents/EDTP.CELDT. pdf.

California Department of Education. (2009a). Standardized testing and reporting (STAR) Program. Internet reports. Explaining 2009 STAR public summary results to the public: Assistance for district and school staff. Retrieved from http://www.cde.ca.gov/ta/tg/sr/resources.asp.

California Department of Education. (2009b). 2008-09 Accountability progress reporting system. 2009 Adequate Yearly Progress report. Information guide. December 2009 revision. Retrieved from http://www.cde.ca.gov/ayp/.

California Department of Education. (2009c). 2009 Academic Performance Index reports. Information guide. May 2009. Retrieved from http://www.cde.ca.gov/api/.

California Department of Education. (2009d). Questions and answers about the California English Language Development Test. Retrieved from http://www.cde.ca.gov/ta/tg/el/documents/celdt09qa.pdf.

California Department of Education. (2010). Dataquest. Retrieved from http://data1.cde.ca.gov/ dataquest/.

California Department of Education. (2011a). Selected statewide data for the year 2010-11. Retrieved from http://data1.cde.ca.gov/dataquest/Cbeds1.asp?Enroll=on\&PctEL=on\&PctFEP=on\&PctRe= on $\& c$ Choice $=$ StatProf $1 \& c$ Year $=2010-11 \& c$ Level $=$ State $\&$ Topic $=$ Profile $\&$ myTimeFrame $=$ S\&submit1=Submit.

California Department of Education. (2011b). 2011 STAR test results: English learners enrolled in school in the U.S. 12 months or more-California Standards Test Scores. Retrieved from http://star.cde.ca. gov/star2011/ViewReport.aspx?ps=true \&1stTestYear=2011\&1stTestType=C\&1stCounty $=$ $\& 1$ stDistrict=\&1stSchool=\&1stGroup=4\&1stSubGroup $=180$.

California Department of Education. (2011c). 2011 STAR test results: English Only-California Standards Test Scores. Retrieved from http://star.cde.ca.gov/star2011/ViewReport.aspx?ps=true\&lstTestYear= $2011 \& 1$ stTestType $=C \& 1$ stCounty $=\& 1$ stDistrict $=\& 1$ stSchool $=\& 1$ stGroup $=4 \& 1$ stSubGroup $=180$.

California Department of Education. (2012a). English learner students by language by grade. http:// data1.cde.ca.gov/dataquest/SpringData/StudentsByLanguage.aspx?Level=State\&TheYear=2011$12 \&$ SubGroup $=$ All $\&$ ShortYear $=1112 \&$ GenderGroup $=$ B $\&$ CDSCode $=$ $00000000000000 \&$ RecordType $=$ EL.

California Department of Education. (2012b). Facts about English learners in California - CalEdFacts. Retrieved from http://www.cde.ca.gov/ds/sd/cb/cefelfacts.asp.

California Department of Education. (2013). California English Language Development Test (Results, 2011-12). Retrieved from http://dq.cde.ca.gov/dataquest/CELDT/results.aspx year=20112012\&level=state $\&$ assessment $=2 \&$ subgroup $=1 \&$ entity $=$.

Callahan, R. M. (2005). Tracking and high school English learners: Limiting opportunity to learn. American Educational Research Journal, 42(2), 305-328.

Callahan, R. M., Wilkinson, L., \& Muller, C. (2010). Academic achievement and course taking among language minority youth. Educational Evaluation and Policy Analysis, 32(1), 84-112.

Callahan, R. M., Wilkinson, L., Muller, C., \& Frisco, M. (2009). ESL placement and schools: Effects on immigrant achievement. Educational Policy, 23(2), 355-384.

Capps, R., Fix, M., Murray, J., Ost, J., Passel, J. S. \& Herwantoro, S. (2005). The new demography of America's schools: Immigration and the No Child Left Behind Act. Washington, DC.

Carhill, A., Suárez-Orozco, C., \& Páez, M. (2008). Explaining English language proficiency among adolescent immigrant students. American Educational Research Journal, 45(4), 1155-1179.

Carnegie Corporation of New York. (1989). Turning points: Preparing American Youth for the 21st century. New York: Carnegie Corporation of New York.

Dutro, S., \& Kinsella, K. (2010). English language development: Issues and implementation at grades six through twelve. In F. Ong \& V. Aguila (Eds.), Improving education for English learners: Researchbased approaches (pp. 151-207). Sacramento: California Department of Education. 
Eccles, J. S. (2008). Can middle school reform increase high school graduation rates? (No. 12). University of California, Santa Barbara: California Dropout Research Project.

Eccles, J. S., \& Midgley, C. (1989). Stage-environment fit: Developmentally appropriate classrooms for young adolescents. In R. Ames \& C. Ames (Eds.), Research on motivation in education (vol. 3, pp. 139-186). Orlando: Academic Press.

Eccles, J. S., Midgley, C., \& Alder, T. F. (1984). Grade-related changes in the school environment: Effects on achievement motivation. In J. G. Nicholls (Ed.), The development of achievement motivation (pp. 283-332). Greenwich, CT: JAI Press.

Eccles, J., Midgley, C., Buchanan, C., Wigfield, A., Reuman, D., Flanagan, C., et al. (1993). Development during adolescence: The impact of stage/environment fit on young adolescents' experiences in schools and families. American Psychologist, 48(2), 90-101.

Estrada, P. (1996). Teacher support during the transition to middle school and its relation to education functioning in poor urban youth. Paper presented at the American Educational Research Association, Atlanta, GA.

Estrada, P., \& Wang, H. (2013). Reclassifying and not reclassifying English learners to fluent English proficient, year 1 findings: Factors impeding and facilitating reclassification and access to the core. Paper presented at the American Educational Research Association, San Francisco, California.

Flores, E., Painter, G., \& Pachon, H. (2009). Qué pasa? Are ELL students remaining in English learning classes too long?. Los Angeles: Tomás Rivera Policy Institute, School of Policy, Planning and Development, University of Southern California.

Freeman, Y., \& Freeman, D. (2002). Closing the gap: How to reach limited-formal-schooling and longterm English learners. Portsmouth, NH: Heinemann.

Genesee, F., Lindholm-Leary, K., Saunders, W., \& Christian, D. (2006). Educating English language learners: A synthesis of research evidence. New York: Cambridge University Press.

Goldenberg, C. (2011). Reading instruction for English language learners. In M. L. Kamil, D. Pearson, E. Moje, R. Birr, \& P. Alfflerbach (Eds.), Handbook on reading research (Vol. IV, pp. 684-710). New York: Routledge.

Goldenberg, C. (2013). Unlocking the research on English learners: What we know-and don't yet know about effective instruction. American Educator, 27 No. 2(Summer), 4-13.

Hallinan, M. T. (1994). School differences in tracking effects on achievement. Social Forces, 72(3), 799-820.

Hallinan, M., \& Kubitschek, W. N. (1999). Curriculum differentiation and high school achievement. Social Psychology of Education, 3, 41-42.

Kim, J., \& Herman, L. J. (2010). When to exit ELL students: Monitoring subsequent success and failure in mainstream classrooms after ELLs' reclassification. National Center for Research on Evaluation, Standards, and Student Testing: University of California, Los Angeles, CA.

Kolesch, N., Walqui, A., Hamburger, L., Gaarder, D., Insaurralde, A., et al. (2010). What are we doing to middle school English learners? Findings and recommendations for change from a study of California EL Programs (Research Report). San Francisco, CA: WestEd.

Kurlaender, M., Reardon, S., \& Jackson, J. (2008). Middle school predictors of high school achievement in three California school districts (No. 13). University of California. Santa Barbara: California Dropout Project.

Lee, O., Quinn, H., \& Valdés, G. (2013). Science and language for English language learners in relation to Next Generation Science Standards and with implications for Common Core State Standards for English language arts and mathematics. Educational Researcher, 42, 223-233.

Linquanti, R. (2001). The redesignation dilemma: Challenges and choices in fostering meaningful accountability for English learners (No. 2001-1). Oakland, CA: University of California Linguistic Minority Research Institute.

Linquanti, R., \& Cook, H. G. (2013). Toward a common definition of English learners: Guidance for states and state assessment consortia in defining and addressing policy and technical issues and options. Washington, DC: Council of Chief State School Officers.

Menken, K., Kleyn, T., \& Chae, N. (2012). Spotlight on "long-term English language learners": Characteristics and prior schooling experiences of an invisible population. International Multilingual Research Journal, 6, 121-142.

Miles, M., \& Huberman, M. (1984). Qualitative data analysis: A source book for new methods. Thousand Oaks, CA: Sage.

Moll, L. C., Amanti, C., Neff, D., \& Gonzalez, N. (1992). Funds of knowledge for teaching: Using a qualitative approach to connect homes and classrooms. Theory into Practice, 31, 132-141. 
No Child Left Behind Act of 2001, Pub. L. No. 107-110. 67 Stat 231 (2002).

Oakes, J. (1990). Tracking and ability grouping: A structural barrier to access and achievement. In J. I. Goodlad \& P. Keating (Eds.), Access to knowledge: An agenda for our nation's schools. New York: College Entrance Examination Board.

Oakes, J., \& Lipton, M. (1999). Teaching to change the world. New York: McGraw Hill College.

Olsen, L. (1997). Made in America: Immigrant students in our public schools. New York: New Press.

Olsen, L. (2010). Reparable harm: Fulfilling the unkept promise of educational opportunity for California's long-term English learners. Retrieved from http://www.californianstogether.org/.

Parrish, T. B., Perez, M., Merickel, A., \& Linquanti, R. (2006). Effects of the implementation of Proposition 227 on the education of English learners, K-12. Washington, DC: American Institutes for Research.

Ragan, A., \& Lesaux, N. (2006). Federal, state, and district level English language learner program entry and exit requirements: Effects on the education of language minority learners. Education Policy Analysis Archives, 14(20), 1-29.

Ruiz-de-Velasco, J., \& Fix, M. (2000). Overlooked and underserved: Immigrant students in U.S. secondary schools. Washington, DC: Urban Institute.

Rumberger, R. W., \& Lim, S. A. (2008). Why students drop out of school: 25 years of research (No. \#15). Santa Barbara: University of California Dropout Research Project.

Saunders, W. M., \& Goldenberg, C. (2010). Research to guide English language development instruction. In F. Ong \& V. Aguila (Eds.), Improving education for English learners: Research-based approaches (pp. 21-81). Sacramento: California Department of Education.

Saunders, W., Goldenberg, C., \& Marcelletti, D. (2013). English language development: Guidelines for instruction. American Educator, 27 No. 2(Summer), 13-25.

Slavin, R. E. (1987). Ability grouping and student achievement in elementary schools: A best-evidence synthesis. Review of Educational Research, 57(3), 293-336.

Slavin, R. E. (1989). Grouping for instruction in the elementary school. In R. E. Slavin (Ed.), School and classroom organization (pp. 159-172). Hillsdale, NJ: Earlbaum.

U.S. Department of Education (2008-09). Consolidated State Performance Reports (CSPR), SY2008-09. Retrieved from www.2.ed.gov/admins/lead/account/consolidated/index.html (Section 1.6.2 Student Demographic Data).

Valdés, G. (2001). Learning and not learning English: Latino students in American schools. New York: Teachers College Press.

Valenzuela, A. (1999). Subtractive schooling: U.S.-Mexican youth and the politics of caring. New York: State University of New York Press.

Williams, T., Hakuta, K., Haertel, E., et al. (2007). Similar English learner students, different results: Why do some schools do better?. Mountain View, CA: EdSource.

Williams, T., Kirst, M. W., Haertel, E., et al. (2010). Gaining ground in the middle grades: Why some schools do better. Mountain View, CA: EdSource.

Working Group on ELL Policy. (2010). Improving educational outcomes for English language learners: Recommendations for the reauthorization of the Elementary and Secondary Education Act. Retrieved from http://ellpolicy.org/.

Yin, R. K. (1989). Case study research. Beverly Hills, CA: Sage.

Yoon, B. (2008). Uninvited guests: The influence of teachers' role and pedagogies on the positioning of English language learners in the regular classroom. American Educational Research Journal, 45(2), 495-522. 